\title{
Spatiotemporal variability of agricultural drought and its association with climatic variables in the Upper Awash Basin, Ethiopia
}

\author{
Getachew Bayable ${ }^{1} \cdot$ Temesgen Gashaw $^{1}$
}

Received: 25 November 2020 / Accepted: 5 March 2021 / Published online: 17 March 2021

(C) The Author(s) 2021 OPEN

\begin{abstract}
Drought is a serious threat to agriculture in Ethiopia. This study examined the spatiotemporal variability of agricultural drought and its association with climatic variables in the Upper Awash basin. Mann-Kendall (MK) trend test was employed to examine the drought trend while Sen's slop estimator and pixel-based linear regression model were used to analyze the magnitude of drought changes. The association between agricultural drought and climatic variables was evaluated by the Pearson correlation coefficient ( $r$ ). High spatiotemporal variability of drought was observed in Kiremit (June-September) and Belg (February-May) seasons. The Belg season spatial average vegetation condition index (VCl) trends were decreased insignificantly from 2001 to 2019 at a 5\% significant level, whereas the spatial average VCI trends of Kiremit season were increased insignificantly. The return period of severe droughts during the Belg season was less frequent than the Kiremt season severe drought. The correlation between spatial average VCl and precipitation was positive for Belg and Kiremit seasons. Likewise, the correlation between average VCl and land surface temperature (LST) was negative in Belg and positive in Kiremit season. Moreover, the correlation between mean VCl and Pacific Ocean Sea Surface Temperature (SST) was positive for Belg and Kiremit seasons. The influencing factor of precipitation and LST on $\mathrm{VCl}$ during Belg season was higher than Kiremit season. The findings of this study are vital for decision-making systems and preparing plans to adjust sowing time, select drought-resistant crops, practice in situ water conservation, practice small-scale irrigation and diversify the income of smallholder farmers.
\end{abstract}

Keywords Drought $\cdot$ LST $\cdot$ Spatiotemporal variability $\cdot$ SST $\cdot$ Trend $\cdot$ VCI

\section{Introduction}

Drought is one of the most devastating natural hazards [1], which are affecting ecosystem functions and services [2, 3]. Depending on the duration and impact of the water cycle component, droughts can be classified into a meteorological drought (e.g., no precipitation over a long period), hydrological drought (e.g., insufficient surface and groundwater water supply), and agricultural drought (e.g., lack of availability of water for a plant or vegetation growth) $[4$, 5]. Drought can result in soil degradation, desertification, water shortages, plant death, and fires [6-8]. Drought can also affect crop development, agricultural and socio-economic activities, and also contributes to social crises and political problems [9-11]. Drought-affected areas develop slowly as the signs of plant moisture stress often change gradually [12]. Thus, understanding the extent and frequency of drought and its relationship with climatic variables is imperative to improve agricultural productivity and ensure sustainable socio-economic development [13].

Several methods are available in the literature for monitoring drought [14-16]. Of these methods, the traditional drought detection methods are based primarily on precipitation, soil moisture, temperature, evaporation, and

Getachew Bayable, bayable.geta@gmail.com; Temesgen Gashaw, gtemesgen114@gmail.com |'Department of Natural Resource Management, College of Agriculture and Environmental Science, Bahir Dar University, Bahir Dar, Ethiopia. 
surface runoff [17]. In this case, spatial interpolation can be obtained from point data. However, several factors affect the interpolation process, so there may be some uncertainty in the interpolation results. These include questions about sample size, spatial distribution, and missing data $[13,15,16]$. As a result, satellite remote sensing has become one of the important techniques for earth observation and drought monitoring and can provide comprehensive information on the dynamics and processes of terrestrial systems [18]. Recently, remote sensing is known to be a powerful tool for assessing the spatiotemporal variability of drought [19-21].

Globally, numerous remotely sensing vegetative drought indices have been established to monitor droughts, such as Normalized Difference Vegetation Index (NDVI), Vegetation Condition Index (VCl), and Vegetation Temperature Condition Index (VTCI) [22-26]. Of these indices, the NDVI is easy to calculate and can be used to consider long-term series. But it is less reliable when monitoring the drought in the heterogeneous area. This is due to the effect of geographical location, ecological system, and soil conditions [27, 28]. To overcome these problems, Kogan [27] developed $\mathrm{VCl}$ for a specific region. The $\mathrm{VCl}$ reflects the overall effect of rainfall, soil moisture, weather, and agricultural practices. Hence, in areas such as the Upper Awash basin, which has different ecosystems and heterogeneous topography, $\mathrm{VCl}$ is vital to compare the impact of weather in areas with different ecological and economic resources, as the index captures rainfall dynamics better than NDVI, particularly in geographically heterogeneous areas. For this reason, it is considered an ideal indicator for large-scale drought monitoring [22, 27, 29]. In earlier times, $\mathrm{VCl}$ was applied in drought monitoring and analysis [13,30-33], and its reliability has been verified by many studies [16, 33-36]. As a result, VCI was used in this study as an indicator of drought [13]. The VCl can describe the spatiotemporal variation in land cover and vegetation. It also helps to distinguish meteorological impacts on vegetation [16].

In East Africa in general and in Ethiopia in particular, droughts have recurred in the last decades and is a major natural disaster that contributes to food insecurity and poverty [37-39]. In Ethiopia, the availability of drought has increased due to climate change and will cause a decline in water and agricultural production [40]. The economy of more than $85 \%$ of the Ethiopian population mainly depends on rain-fed agriculture, which is vulnerable to climate change [41]. According to Funk et al.[42], 2015 was the driest year in most parts of Ethiopia. As a result, the main rainy season was late and below normal [41]. The El Niño-Southern Oscillation (ENSO) was the ultimate cause of this drought. More specifically, the warmer stage (EI $\mathrm{Niño)}$ is closely associated with reserve rainfall during the main rainy season in central Ethiopia, including the Upper Awash basin [43]. In such conditions, the moisture requirements of plants cannot be met, leading to a sharp decline in plant production. Drought is one of the most frequent environmental threats in the Upper Awash basin of Ethiopia [44]. Besides, Edossa et al. [45] has also reported the existence of extreme meteorological drought events in the Upper Awash basin. Based on the socio-economic analysis, Desalegn et al.[44] also indicated that the Upper Awash basin experiences drought every two years. However, the spatiotemporal variability of agricultural drought and its association with climatic variables are not well-understood in the Upper Awash basin. Besides, the spatial and temporal variation of agricultural drought across agro-ecological zones in the basin is not known. This type of study has immense importance for developing an understanding of the basics of basin vegetation dynamics and thus helps in policymaking. Evaluation of spatiotemporal variability of agricultural drought and its association with climatic elements is important for policy-makers and planners for establishing effective and comprehensive monitoring and early warning system to reduce the adverse impacts of drought. Therefore, this study was aimed to examine the spatiotemporal variability of agricultural drought and its association with climatic elements (such as precipitation, LST and Pacific Ocean SST) in the Upper Awash basin of Ethiopia. Specifically, the objectives of this study were: i) to assess the spatiotemporal variability of agricultural drought, ii) to examine the frequency of agricultural drought, and iii) to evaluate the association between VCI and climatic variables in the Upper Awash basin.

\section{Materials and methods}

\subsection{Description of the study area}

The Upper Awash basin is found in the central part of Ethiopia mainly at the western margin of the Main Ethiopian Rift system. Geographically, the basin is located between $8^{\circ} 16^{\prime} \mathrm{N}-9^{\circ} 18^{\prime} \mathrm{N}$ and $37^{\circ} 57^{\prime} \mathrm{E}-39^{\circ} 17^{\prime} \mathrm{E}$, covering $10,640 \mathrm{~km}^{2}$. Its physical settings are characterized by the heterogeneity of the large natural systems such as orographic, the high plains, mountains, and plateaus [46]. The topography undulates between 1587 to $3561 \mathrm{~m}$ a.s.l. The climate of the study area is influenced by undulating mountain chains and the circulatory systems that interact with orography, cross-equatorial wind system, and the movement of the Inter-Tropical Convergence Zone (ITCZ) [46]. The basin's climate is humid at the highlands and arid to semiarid in the escarpment and rift valley [47]. The land-use types are intensively cultivated (67\%), moderately cultivated (25.5\%), bushland or shrubland or wooded 
grassland (4.5\%), and urban area and alpine vegetation (3\%) [48]. Hence, agriculture is the main economic activity. The mixed crop-livestock system is the most important farming system in the plateau and the highland areas. This farming system is dominated by smallholder farmers in rain-fed agriculture with limited but complementary livestock production. Landholdings are generally small and are fragmented into many plots with different land uses. Besides, the main towns found in the Upper Awash basin are characterized by industry and agro-industry.

\subsection{Data types and sources}

Different remotely sensed imageries were used in this study. The Shuttle Radar Topographic Mission (SRTM) Digital Elevation Model (DEM) was acquired from the United States Geological Survey (USGS) (https:/earthexplorer. usgs.gov/). Land use land cover (LULC) data were obtained from Sentinel2 2016 product (http://geoportal.rcmrd.org/ layers/servir\%3Aethiopia_sentinel2_lulc2016). Composite Moderate Imaging Spectrometer (MODIS) Normalized Difference Vegetation Index (MOD13Q1) and Land Surface Temperature (MOD11A2) data for 2001-2019 periods (19 years) were accessed from the Land and Atmospheric Archive System Distributed Active Archive Centre (LAADS DAAC) (https://lpdaac.usgs.gov/products/mod44bv006/\# tools).

Furthermore, satellite precipitation data from Climate Hazards Group Infra-Red Precipitation with Stations (CHIRPS) was used. Monthly Pacific Ocean SST data in the NINO3.4 region was acquired from the National Oceanic and Atmospheric Administration (NOAA) Satellite Mission website (http://www.cgd.ucar.edu/cas/catalog/climind/ TNI_N34/index.html). According to Babu [49] and Zaroug [50], the NINO 3.4 SST data has NINO3 and NINO4 characteristics. Therefore, the Pacific Ocean SST of the NINO3.4 area was also used to evaluate the relationship between the SST and the index of vegetative drought.

\subsection{Remote sensing data processing}

The obtained MOD13Q1 and MOD11A2 data are supported with a sinusoidal projection method in the Hierarchical Data Format (HDF). Through format conversion and reprojection using MODIS Reprojection Tool (MRT), these data were prepared for the Geographic Information System (GIS) program. Using metadata attributes stored in the dataset, the filtering of no data values and cloud deletion from the imagery was performed [51]. MODIS NDVI for sixteen days and MODIS LST datasets for eight days were composite of maximum daily values throughout the year. The noise of these composite datasets was removed using the fast Fourier transform (FFT) algorithm
[51]. Using the forward transformation process, the Fourier transform transforms the spatial domain image into a frequency domain image. Then, using the frequency domain images filtered through the inverse Fourier transform (IFT), an enhanced noise-free image was created [52]. For the two-dimensional cases, the Fourier transform representation for the discrete functions is expressed as the sum of sine and cosine weight and is given in Eq. 1:

$\mathrm{F}(u, v)=\frac{1}{\mathrm{NM}} \sum_{x=0}^{N-1} \sum_{y=0}^{M-1} \mathrm{f}(\mathrm{x}, \mathrm{y}) e^{-2 \pi i\left(\frac{u x}{N}+\frac{v y}{M}\right)}$

where $u$ and $v$ are spatial frequencies, $F(u, v)$ is a function of the frequency domain, $f(x, y)$ is a function of the spatial domain, $i$ is $\sqrt{-1}, N$ is the number of $x$-direction pixels, and $M$ is the number of $y$-direction pixels. $X$ ranges from zero to $\mathrm{N}-1$ and $y$ ranges from zero to $M-1$. Fourier sequences (Fu) have $b$ een multiplied by a low pass filter ( $w$ ), giving the freque ncy domain a filtered signal (wFu). The enhanced image in the spatial domain was reconstructed using the inverse transform after filtering to remove noises related to highfrequency components (Eq. 2):

$f(x, y)=\sum_{u=0}^{N-1} \sum_{v=0}^{M-1} w F(u, v) e^{2 \pi i\left(\frac{u x}{N}+\frac{v y}{M}\right)}$

The MODIS NDVI was converted into required NDVI values between -1 and 1 using the Arc GIS environment using a raster calculator by multiplying the improved image data with a scale factor (0.0001). The total numbers of NDVI images downloaded (2001-2019) for Belg (February-May) and Kiremit (June-September) seasons were 304. Since the MODIS data are available in every 16 days composite, it was converted into monthly solutions. Two 16 days composite images were added and divided by two in the raster calculator to get the mean monthly NDVI for each season. Similarly, the LST of 2001-2019 periods for Belg and Kiremit seasons were derived from eight days of composite MOD11A2. The digital number (DN) of LST was converted to degree Celsius $\left({ }^{\circ} \mathrm{C}\right.$ ) by multiplying the input digital number (image) with a scale factor (0.02) and then subtracting $273.15^{\circ} \mathrm{C}$. A total of $608 \mathrm{LST}$ images were acquired (2001-2019) during Kiremit and Belg seasons. Then, four eight-day composite images were added and divided by four in the raster calculator to get the mean monthly LST for each season.

Most precipitation data from in situ meteorological stations within the Upper Awash basin had an outsized percentage of missing data problems. Moreover, the spatial distributions of stations were not evenly dispersed. During this case, the CHIRPS satellite (https://data.chc. ucsb.edu/products/CHIRPS-2.0/) is an important source of 
precipitation data [53-56]. To determine the accuracy of the CHIRPS satellite precipitation data in the Upper Awash Basin, 19 meteorological gauge station data from the National Meteorological Service Agency (NMSA) of Ethiopia were used as references. The details of these stations are given in Table 1. By taking the average of the previous and subsequent months, monthly missing values were filled. However, those years with an entire missing data were omitted from the analyses [53, 57]. In this study, a surface map in the form of a grid precipitation map for the study area was constructed using the ordinary kriging geostatistical interpolation method. Ordinary kriging is the best linear unbiased estimator and was found to be the best method because it produces little root mean square error [58]. Besides, the Pearson correlation coefficient (r) was used to assess the efficiency of the areal average CHIRPS precipitation product by using the areal average interpolated meteorological rainfall $[54,59]$.

\subsection{Methods for identifying drought}

The short (Belg) and main (Kiremit) rainy seasons determine rain-fed agricultural production in Ethiopia, including the Upper Awash basin [60]. Almost $85 \%$ of the population in the study area practice rain-fed agriculture, which depends on the main and short rainy seasons. The seasonal characteristics of rainfall have a great influence on the production potential of crops in the rain-fed agricultural systems since the availability of water in the soil is essential for the growth of crops and vegetation. MODIS NDVI data were used to derive the Belg and Kiremit seasons $\mathrm{VCl}$. $\mathrm{VCl}$ is most useful during the main growing (Kiremit) and short growing (Belg) seasons because it is a measure of vegetation vigor. The $\mathrm{VCl}$ was determined in Eq. $3[61,62]$ below:

$\mathrm{VCl}=100 \times \frac{\mathrm{NDVI}_{i}-\mathrm{NDVI}_{\text {min }}}{\mathrm{NDVI}_{\text {max }}-\mathrm{NDVI}_{\text {min }}}$

where $\mathrm{VCl}$ is the vegetation condition index of the pixels, $N D V l_{i}$ is the NDVI value of the pixels, and $N D V I_{\text {max }}$ and $\mathrm{NDVI}_{\text {min }}$ are the maximum and minimum NDVI values during 2001-2019 periods, respectively. The numerator refers to the difference between the actual value of the $\mathrm{NDVI}$ and the minimum value of the NDVI for a given time and is representative of the meteorological and vegetation data for a given time. The maximum and minimum denominator values represent the best and the worst vegetation growth conditions, respectively, and the difference of them reflects somewhat the local vegetation condition $[22,27,28]$. The $\mathrm{VCl}$ includes the NDVI with both real-time and historical details. $\mathrm{VCl}$ results range between zero and 100 , where lower $\mathrm{VCl}$ values imply poor growth of vegetation and higher drought levels $[27,28,63,64]$. On the other hand, higher $\mathrm{VCl}$ values are an indicator of good vegetation conditions and characterize lower drought events. Based on $\mathrm{VCl}$, droughts have been classified and the spatial and temporal variations of drought over 2001-2019 time spans were analyzed. In the present analysis, three forms
Table 1 Characteristics of in situ meteorological stations

\begin{tabular}{lllll}
\hline Station Name & Elevation $(\mathrm{m})$ & Longitude $(\mathrm{E})$ & Latitude(N) & Period \\
\hline Abebe Keranso & 2456 & $38.17^{\circ}$ & $8.98^{\circ}$ & $2001-2015$ \\
Addis Ababa Obs & 2386 & $38.75^{\circ}$ & $9.02^{\circ}$ & $2001-2015$ \\
Addis Alem & 2372 & $38.38^{\circ}$ & $9.04^{\circ}$ & $2001-2015$ \\
Akaki & 2057 & $38.79^{\circ}$ & $8.87^{\circ}$ & $2001-2015$ \\
Alem Tena (Add) & 1656 & $38.91^{\circ}$ & $8.29^{\circ}$ & $2001-2015$ \\
Asgori & 2072 & $38.33^{\circ}$ & $8.79^{\circ}$ & $2001-2015$ \\
Boneya & 2251 & $38.64^{\circ}$ & $8.78^{\circ}$ & $2001-2015$ \\
Chefedonsa & 2392 & $39.12^{\circ}$ & $8.97^{\circ}$ & $2001-2015$ \\
Tulu Bolo & 2190 & $38.21^{\circ}$ & $8.65^{\circ}$ & $2001-2015$ \\
Ginchi & 2132 & $38.13^{\circ}$ & $9.02^{\circ}$ & $2001-2015$ \\
Dertu Liben & 1991 & $38.12^{\circ}$ & $8.97^{\circ}$ & $2001-2015$ \\
Dilela & 2429 & $38.04^{\circ}$ & $8.64^{\circ}$ & $2001-2015$ \\
Ejere & 2254 & $39.26^{\circ}$ & $8.77^{\circ}$ & $2001-2015$ \\
Enchini & 2687 & $38.36^{\circ}$ & $9.32^{\circ}$ & $2001-2015$ \\
Hombole & 1743 & $38.77^{\circ}$ & $8.37^{\circ}$ & $2001-2015$ \\
Intoto & 2903 & $38.72^{\circ}$ & $9.08^{\circ}$ & $2001-2015$ \\
Meki & 1662 & $38.82^{\circ}$ & $8.15^{\circ}$ & $2001-2015$ \\
Mojo & 1763 & $39.11^{\circ}$ & $8.61^{\circ}$ & $2001-2015$ \\
Addis Ababa Bole & 2354 & $38.75^{\circ}$ & $9.03^{\circ}$ & $2001-2015$ \\
\hline
\end{tabular}


of $\mathrm{VCl}$ drought classes that are defined by Kogan [28] were used (Table 2).

\subsection{Trend detection of the $\mathrm{VCl}$ drought index}

The pixel-based linear regression model was used to analyze the spatial and temporal trends of $\mathrm{VCl}$ changes pixel-wise using the Belg and Kiremit seasons datasets (2001-2019) (Eq. 4). The positive VCl slope values represent an upward trend while the negative $\mathrm{VCl}$ slope values indicate a downward trend [33]. An upward trend of VCI indicates enhanced vegetation growth and drought reduction while a downward trend of $\mathrm{VCl}$ specifies a reduction of vegetation cover and increasing drought. The trend in the $\mathrm{VCl}$ was calculated using Eq. $4[13,65]$ :

Slope $=\frac{\mathrm{n} \times \sum_{\mathrm{i}=1}^{\mathrm{n}} \operatorname{VCli} \times \mathrm{ti}-\left(\sum_{\mathrm{i}=1}^{\mathrm{n}} \mathrm{VCli}\right)\left(\sum_{\mathrm{i}=1}^{\mathrm{n}} \mathrm{ti}\right)}{\mathrm{n} \times \sum_{\mathrm{i}=1}^{\mathrm{n}} \mathrm{ti}^{2}-\left(\sum_{\mathrm{i}=1}^{\mathrm{n}} \mathrm{ti}\right)^{2}}$

where $\mathrm{VCli}$ is the vegetation condition index for year $\mathrm{i}, \mathrm{n}$ is the duration of the time series $(n=19)$, and ti is the index number for the years 2001 to 2019 (1-19).

In addition to the pixel-based linear regression model, Sen's slope was used to estimate the magnitude of temporal shifts of the areal average $\mathrm{VCl}$ drought index. In contrast to linear regression, this approach is less affected by missing values and outliers $[59,66]$. If there is a linear trend, the magnitude of the monotonous trend can be determined using the nonparametric slope estimator of Sen using Eq. 5 [67]:

$\beta=\operatorname{median}\left(\frac{y j-y i}{j-i}\right)$

where $\beta$ is the median value of the slope values between the yi and yj data measurements in phases $i$ and $j(i<j)$, respectively. The positive value of $\beta$ reflects an upward trend, while a downward trend is shown by the negative value of $\beta$. The sign of $\beta$ represents the course of the data trend, while its value shows the trend's steepness.

The Mann-Kendall trend test was used to determine trends in the time series of areal average $\mathrm{VCl}$ values for the whole basin. This approach is less influenced by missing values and unequal distribution of data and less vulnerable to outliers because the ranks of the observations are

Table 2 VCl-based drought classification

\begin{tabular}{lll}
\hline Class & Type & VCl (\%) \\
\hline 1 & Normal & $>50$ \\
2 & Drought & $35-50$ \\
3 & Severe Drought & $<35$ \\
\hline
\end{tabular}

taken into account rather than their actual values $[55,68]$. The null hypothesis ( $\mathrm{H} 0$ ) of no trend, that is, the Yi observations are randomly ordered in time, against the alternative hypothesis ( $\mathrm{H} 1$ ), according to the Mann-Kendall trend test, where a monotonic (increasing or decreasing) trend was checked in the time series. MK statistics $S$ are computed based on Yue et al. [68] and Mann [69] using Eq. 6:

$S=\sum_{i=1}^{n-1} \sum_{j=i+1}^{n} \operatorname{Sign}(y j-y i)$

where $Y i$ and $Y j$ are sequential data values for $n$-length data of the time series and

$\operatorname{Sign}(y j-y i)= \begin{cases}1 & \text { if }(y j-y i)>0 \\ 0 & \text { if }(y j-y i)=0 \\ -1 & \text { if }(y j-y i)<0\end{cases}$

If the dataset is distributed identically and independently, then S's mean is zero, and S's variance is given by Eq. 8:

$\operatorname{Var}(\mathrm{S})=\frac{1}{18}\left[n(n-1)(2 n+5)-\sum_{i=0}^{m} \mathrm{ti}(\mathrm{ti}-1)(2 \mathrm{ti}+5)\right]$

where $n$ is the dataset length, $m$ is the number of tied groups in the time series (a tied group is a collection of sample data with the same value), and ti is the number of data points in the ith group.

The $Z$ statistics are calculated using Eq. 9:

$Z= \begin{cases}\frac{S+1}{\sqrt{\operatorname{Var}(S)}} & \text { for } S<0 \\ 0 & \text { for } S=0 \\ \frac{S-1}{\sqrt{\operatorname{Var}(S)}} & \text { for } S>0\end{cases}$

To test either an upward or downward monotone trend, a significance level alpha (a) was used. By comparing the computed $Z$ with critical values, the decision for the twotail test was made. The null hypothesis is rejected if the computed $Z$ absolute value is greater than the critical value, or if the $p$-value is less than the selected significance level ( $a=0.05$ or 0.1 ). The direction of trends is upward for positive Z-value and downward for negative Z-value when the null hypothesis is rejected [70]. The result is said to be statistically significant if the null hypothesis is rejected as in Figs. 1 and 2.

\subsection{Exceedance probability and return periods}

Using Weibull's frequency distribution equation, the $\mathrm{VCl}$ exceedance probability and return periods were 


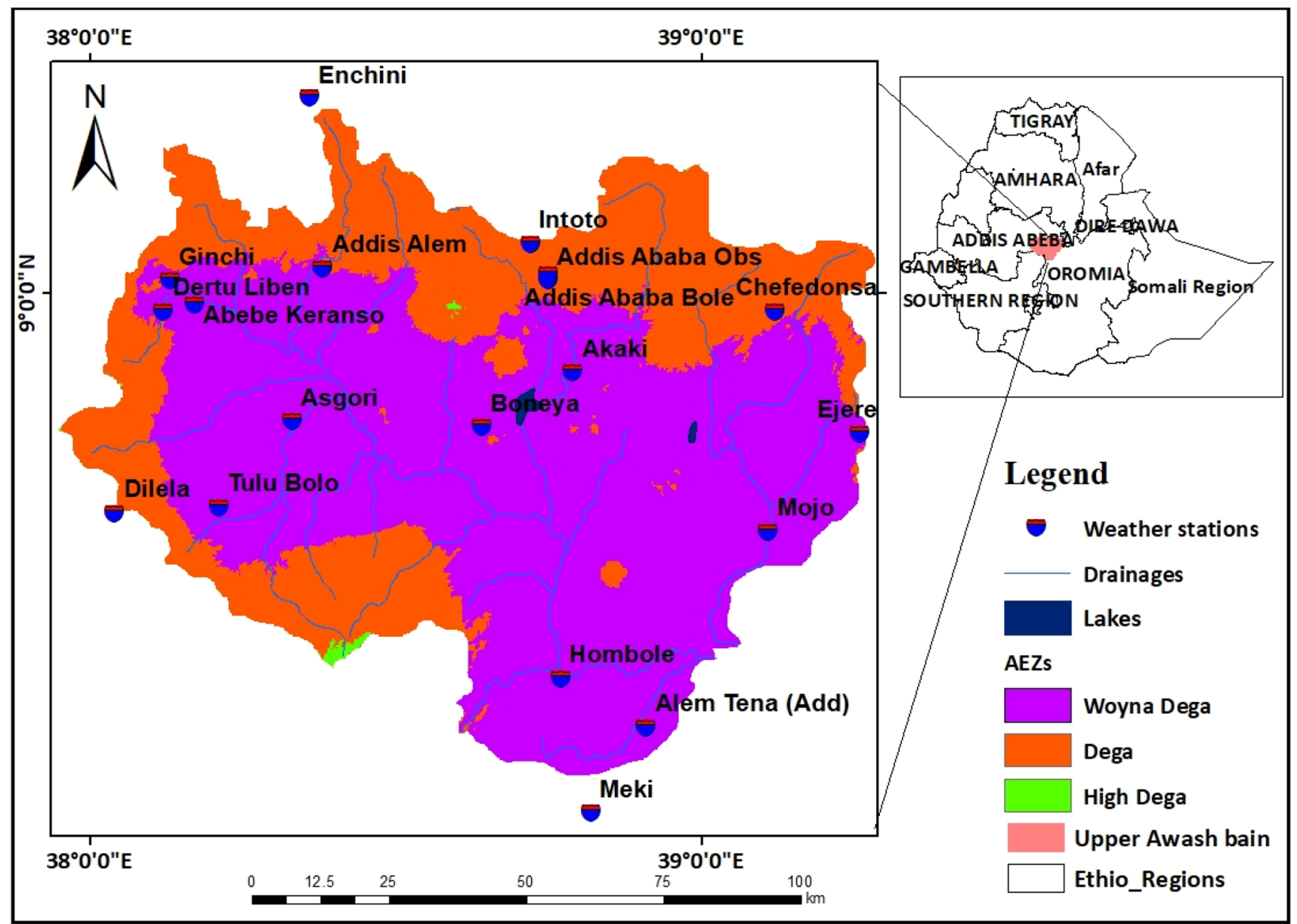

Fig. 1 Location map of the study basin

determined [71]. The return period and the probability of exceeding each other are reciprocal (Eq. 10).

$\operatorname{Tr}=\frac{n+1}{m}=\frac{1}{p(x m)}$

where $\mathrm{p}(\mathrm{xm})$ is the probability of exceedance, $\operatorname{Tr}$ is the return duration that implies an average number of years that will be equalled or exceeded during a given case, $n$ is the total number of study years (19 years), and $m$ is the rank of observations in descending order.

\subsection{Correlation analysis of the $\mathrm{VCl}$ and climate variability}

The degree and direction of the relationship between two variables are expressed in the Pearson correlation coefficient $(r)[33,72]$. The greater association between the two variables is demonstrated by a larger absolute value. To evaluate the relationship between drought and climatic factors (precipitation, LST, and SST), the Pearson correlation coefficient was used. The coefficients of Pearson correlation were determined using Eq. 11 [73]:

$r=\frac{\sum_{i=1}^{n}(X i-\bar{X})(Y i-\bar{Y})}{\sqrt{\sum_{i=1}^{n}(X i-\bar{X})^{2} \sum_{i=1}^{n}(Y i-\bar{Y})^{2}}}$

where $r$ is the coefficient of correlation, $n$ is the time series duration and $i$ is the number of years during the periods studied (1-19). Xi and $\mathrm{Yi}$ are the $\mathrm{VCl}$ and the value of climate variability in the year $i$, respectively, and $\bar{X}$ and $\bar{Y}$ are the mean $\mathrm{VCl}$ and the mean climate variability during the study periods, respectively.

\section{Results and discussion}

\subsection{Evaluation of CHIRPS precipitation data}

The results of the comparison between the areal average CHIRPS and areal average interpolated meteorological 


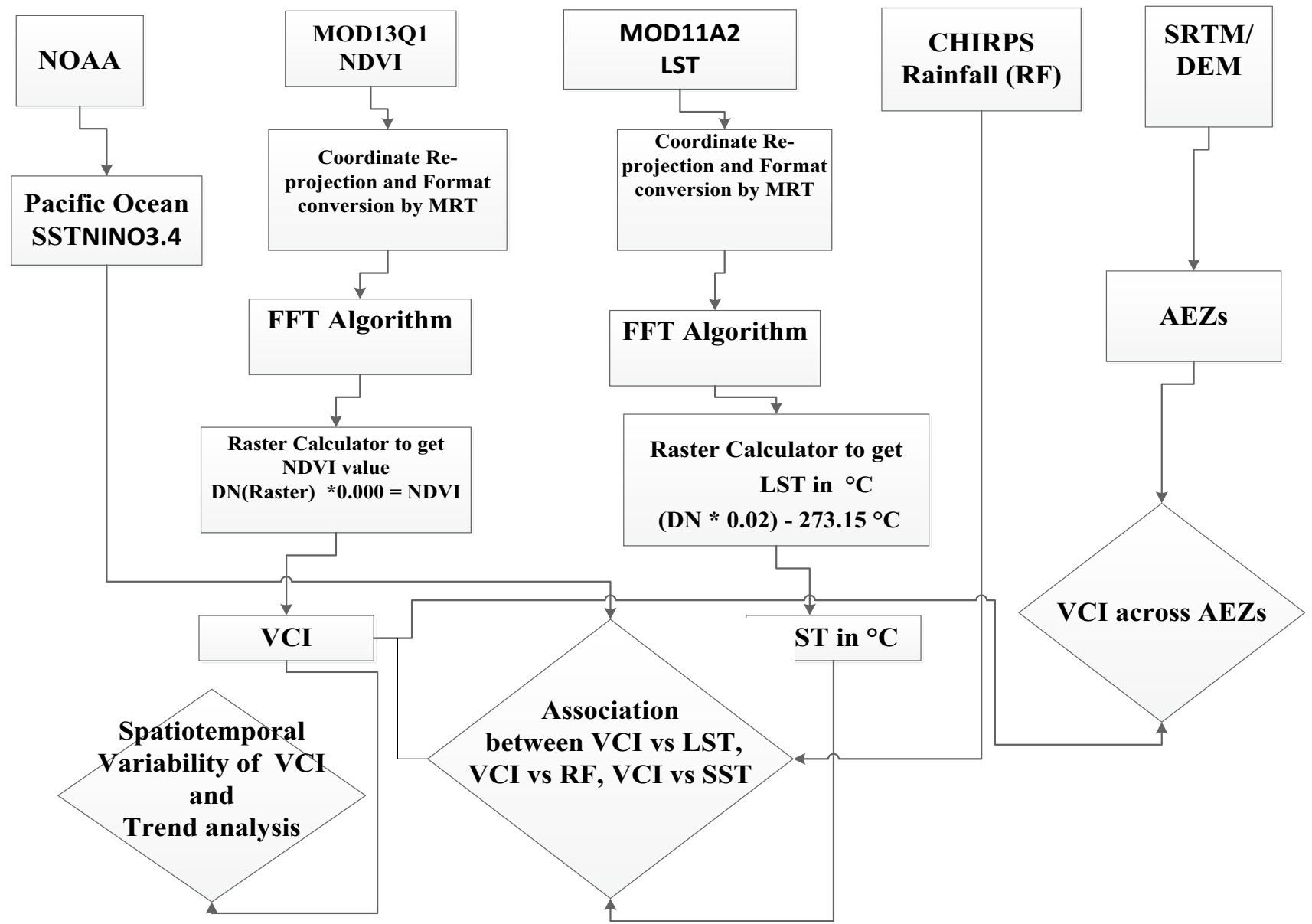

Fig. 2 Methodological flowchart of the study

station rainfall during the Belg and Kiremit seasons for the periods 2001 to 2015 are shown in Fig. 3a and b. A very good agreement was observed between areal average observed rainfall and CHIRPS precipitation product (Fig. $3 a$ and $b$ ). The findings of this study agreed with a study carried out by Ayehu et al. [74] in the Upper Blue Nile basin; Belay et al. [55] in the Beles basin; Alemu and Bawoke [59] in the Amhara regions of Ethiopia; and Dinku et al. [54] in Eastern Africa.
Fig. 3 Comparisons between the areal average CHIRPS and areal average interpolated meteorological station rainfall data during Belg (a) and Kiremit (b) seasons in the Upper Awash basin (2001-2015)
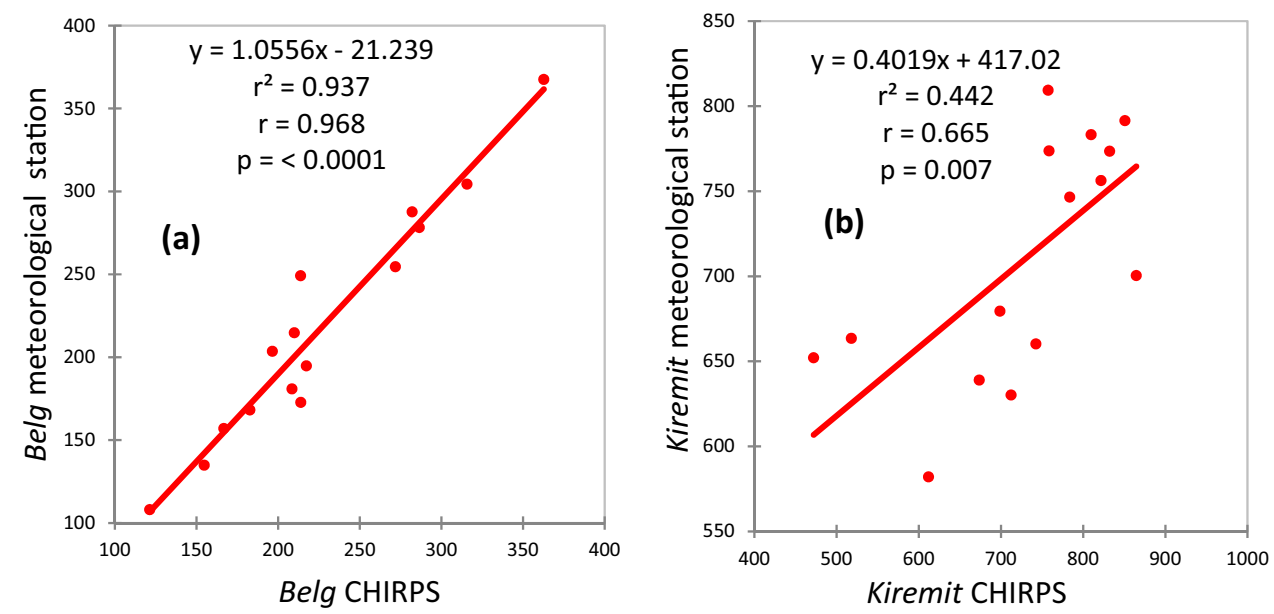

SN Applied Sciences 


\subsection{Temporal variation of vegetation condition index ( $\mathrm{VCl})$}

\subsubsection{Belg and Kiremit seasons yearly variations of drought index ( $\mathrm{VCl})$}

The yearly variations of the $\mathrm{VCl}$ drought index from 2001 to 2019 periods during the Belg and Kiremit seasons are shown in Fig. 4. The lines parallel to the $\mathrm{X}$-axis in Fig. 4 represent the threshold values of $\mathrm{VCl}$ for severe drought $(\mathrm{VCl} \leq 35 \%)$ and drought $(35 \% \leq \mathrm{VCl} \leq 50 \%)$. During the Belg season, severe droughts occurred in the years 2008, 2009, 2011, 2012, 2013, 2014, and 2015 while normal droughts were observed in 2002, 2016, and 2019 years (Fig. 4). The findings of this study were consistent with the years of historical drought in Ethiopia. Drought years in Ethiopia include 1984, 1987, 1991/1992, 1993/1994, 2002, 2008/2009, 2011/2012, and 2015 [53, 66]. The year 2015 was the driest in most parts of Ethiopia as a result of El Niño [42]. Likewise, in the Kiremit season, the severe drought years were identified in the years 2003, 2009, 2010, 2012, and 2014, whereas normal drought years were identified during 2001-2016 except 2003, 2009, 2010, 2012, and 2014 years in the Upper Awash basin (Fig. 4). Similarly, Liou and Mulualem [40] find that 2002, 2004, 2008, 2009, 2012, 2014 and 2015 were severe drought years in the northern, central and eastern parts of Ethiopia during Kiremit season. The most severe drought years in the study basin were identified during the Belg season. On the other hand, during the Belg season, the maximum $\mathrm{VCl}(\mathrm{VCl}>70 \%)$ was observed in 2001 and 2010 years. Likewise, the maximum $\mathrm{VCl}(\mathrm{VCl}>70 \%)$ was reported in 2017 in Kiremit season. Overall, VCI was enhanced from 2003-2007 and 2017-2019 during the Belg season. The enhancement of $\mathrm{VCl}$ was also observed from 2017-2019 during the Kiremit season (Fig. 4).

The Belg and Kiremit season spatial mean VCl from 2001 to 2019 periods was $45.4 \%$ and $42.0 \%$, respectively. The Kiremit season VCI was increased insignificantly at the rate of $0.395 \% \mathrm{yr}^{-1}$ over the whole basin while Belg season $\mathrm{VCl}$ was decreased insignificantly at the rate of $0.693 \% \mathrm{yr}^{-1}$ over the basin at a $5 \%$ significant level (Table 3). It indicates that the trend of drought in the Upper Awash basin was decreased and increased insignificantly during Kiremit and Belg season, respectively. Similarly, Shen et al. [16] indicated that the mean annual VCl of China from 1982 to 2010 was slowly increased, indicating that the enhanced vegetation growth and the drought alleviated. Liang et al. [13] also reported the increased trend of VCl in China from 1981 to 2015 during the spring, summer, and autumn seasons, indicating that drought was decreased in China during these periods(1981-2015). On the contrary, Gidey et a1 [75]. reported that the Vegetation Health Index (VHI) value in
Fig. 4 Belg and Kiremit season yearly variations of drought index (VCl) in the Upper Awash basin during the study periods (2001-2019)

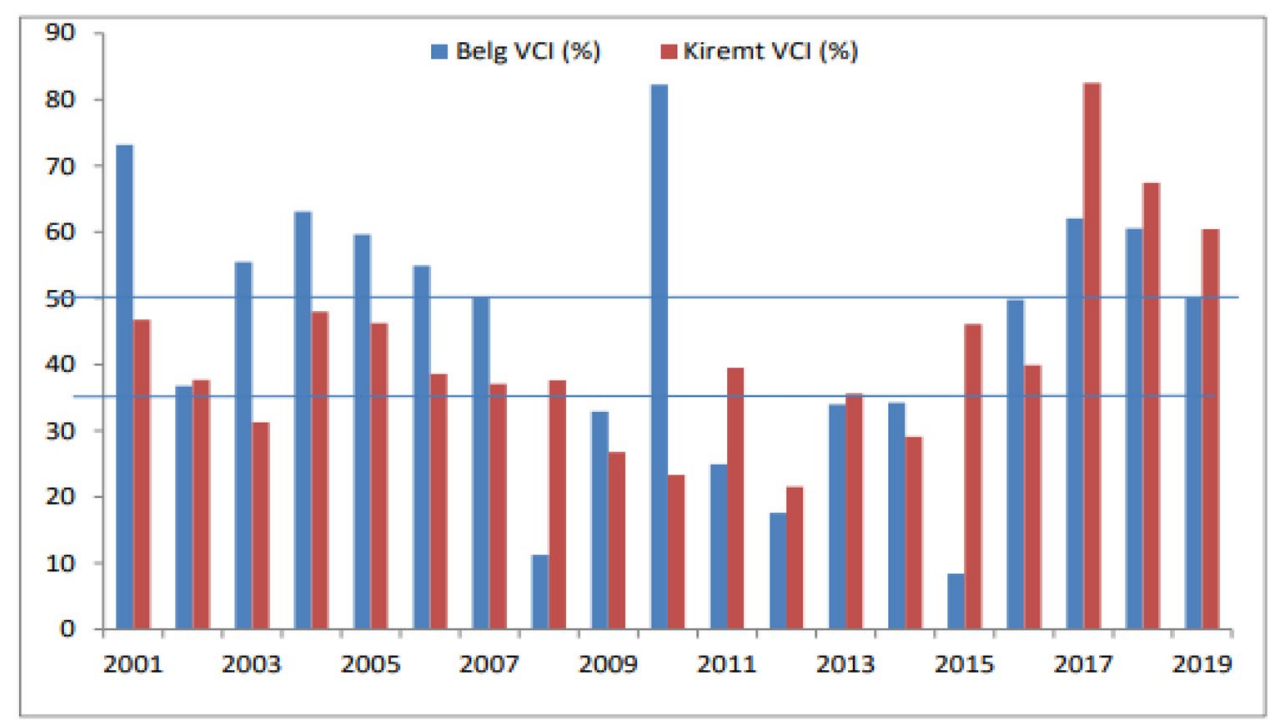

\begin{tabular}{lllllllc}
\hline & a & Kendall's tau & S & p-value & Trend & Significance & $\begin{array}{l}\text { Sen's } \\
\text { Slope (\%/ } \\
\text { year) }\end{array}$ \\
\hline Kiremit & 0.05 & 0.099 & 17 & 0.576 & Upward & Insignificant & 0.395 \\
Belg & 0.05 & -0.170 & -29 & 0.327 & Downward & Insignificant & -0.693 \\
\hline
\end{tabular}

Table 3 The Mann-Kendall trend analysis of areal average $\mathrm{VCl}(\%)$ (2001-2019) during Kiremit and Belg seasons
SN Applied Sciences A SPRINGER NATURE journal 
Raya (northern Ethiopia) was reduced significantly during the Kiremit season from 2001 to 2015.

\subsubsection{Belg and Kiremit season yearly variation of vegeta- tion condition index ( $\mathrm{VCl}$ ) across agro-ecological zones (AEZs)}

Agro-ecological zoning can be characterized as a spatial division of the landscape into comparatively similar agricultural and ecological features [76], providing a context for understanding the complexity of agro-ecological systems [77]. Topography plays an important role in the agricultural zone in mountainous countries such as Ethiopia, where Africa's most prominent mountain system is located [76]. The elevation-based agro-ecological zoning developed by Hurni [76] was therefore adopted to classify the basin into three agro-ecological zones (AEZs). These AEZs are locally referred to as Weyna Dega (subtropical) (1500-2300 m.a.s.l), Dega (temperate) (2300-3200 m.a.s.l) and High Dega (Alpine) (3200-3700 m.a.s.l) [76]. Because of its good vertical and horizontal precision, this classification was performed using a $30 \mathrm{~m}$ SRTM DEM spatial resolution [78]. To improve agricultural development planning, agronomic zoning is generally significant, as agronomic regions are heavily dependent on climatic parameters such as rainfall quantity and variability, temperature, and vegetation characteristics [76]. It is important to understand the occurrence of drought in the key agronomic regions of the basin. This then helps to recognize the most drought-affected agro-ecological areas, which in turn will enable decision-makers to establish environmentally sound drought-friendly strategies.

Understanding the yearly variation of $\mathrm{VCl}$ distributions across agro-ecological zones (AEZs) enables us to identify areas experiencing severe droughts. The annual variation of vegetative drought index in different AEZs of Upper Awash basin during Belg season in the study periods (2001-2019) is shown in Fig. 5. In the Belg season, VCI was decreased insignificantly at the rate of $0.817 \% \mathrm{yr}^{-1}$ and $0.552 \% \mathrm{yr}^{-1}$ in Woyna Dega and Dega AEZ, respectively (Table 4). But VCI was decreased significantly at the rate of $2.174 \% \mathrm{yr}^{-1}$ in High Dega AEZ (Table 4). During Belg season, the most severe drought years were identified in Woyna Dega AEZ while most none drought years were identified in High Dega AEZ. In Woyna Dega AEZ, severe drought years mainly occurred in 2002, 2008, 2009, 2011, 2012, 2013, 2014, and 2015. In Dega AEZ, severe droughts were identified in 2008, 2009, 2011, 2012, and 2015 years. Similarly, in High Dega AEZ severe drought years were identified in 2008, 2012, and 2015 (Fig. 5).

Similarly, the temporal variation of vegetative drought index in different AEZs during Kiremit season from 2001

Fig. 5 The Belg season yearly variations of drought index (VCI) in different AEZs of Upper Awash basin during 2001-2019 periods

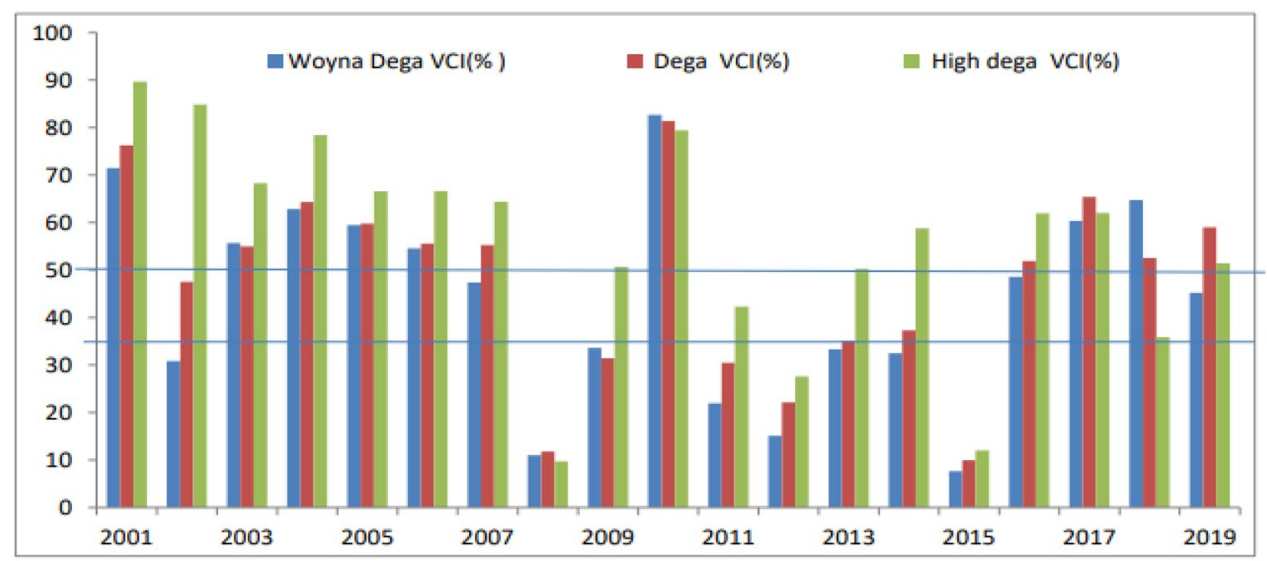

Table 4 The Mann-Kendall trend analysis of areal average VCI (\%) (2001-2019) across AEZs

\begin{tabular}{lllllllll}
\hline Season & AEZs & $a$ & Kendall's tau & S & p-value & Trend & Significance & Sen's slope(\%/year) \\
\hline \multirow{2}{*}{ Belg } & Woyna Dega & 0.05 & -0.146 & -25 & 0.401 & Downward & Insignificant & -0.817 \\
& Dega & 0.05 & -0.135 & -23 & 0.441 & Downward & Insignificant & -0.552 \\
& High Dega & 0.05 & -0.462 & -79 & $0.006^{*}$ & Downward & significant & -2.174 \\
\multirow{3}{*}{ Kiremit } & Woyna Dega & 0.05 & 0.123 & 21 & 0.484 & Upward & Insignificant & 0.729 \\
& Dega & 0.05 & 0.146 & 25 & 0.401 & Upward & Insignificant & 0.528 \\
& High Dega & 0.05 & 0.275 & 47 & 0.108 & Upward & Insignificant & 1.096 \\
\hline
\end{tabular}

${ }^{*}$ significant at $\mathrm{a}=0.05$ 
to 2019 is shown in Fig. 6. In the Kiremit season, VCl was increased insignificantly at the rate of $0.528 \% \mathrm{yr}^{-1}$, $0.729 \% \mathrm{yr}^{-1}$, and $1.096 \% \mathrm{yr}^{-1}$ in Woyna Dega, Dega, and High Dega AEZs, respectively (Table 4). During the Kiremit season, the most severe drought years were identified in Woyna Dega and High Dega AEZs while most none drought years were identified in Dega AEZ. In the Kiremit season, severe droughts were identified in the year 2002, 2003, 2006, 2008-2013, and 2014 in Woyna Dega AEZ and 2003, 2004, 2005, 2007, 2009, 2010, and 2014 years in High Dega AEZ. Likewise, severe droughts in Dega AEZ occurred in the years 2003, 2009, 2010, 2012, and 2014 (Fig. 6).

\subsection{Spatial variation of $\mathrm{VCl}$}

The spatial and temporal distributions of pixel-based VCI over Belg and Kiremit seasons during 2001-2019 periods are shown in Figs. 7 and 8, respectively. The result indicated that severe droughts were characterized in the year 2002, 2008, 2009, 2011, 2012, 2013, 2014, and 2015 during the Belg season with a mean VCl of less than $35 \%$ (Fig. 7). The drought years in Ethiopia include 1984, 1987, 1991/1992, 1993/1994, 2002, 2008/2009, 2011/2012, $2015[53,66]$. These drought years either coincide or follow El Nino events [53]. Likewise, severe droughts were identified in the year 2002, 2003, 2009, 2010, 2012, 2013, and 2014 during the Kiremit season (Fig. 8). The finding of this study aligned with Liou and Mulualem [40], who reported that 2002, 2004, 2008, 2009, 2012, 2014 and 2015 were severe drought years in the northern, central and eastern parts of Ethiopia during the growing (Kiremit) season. Measho et al. [79] also reported that the years of 2000, 2008, 2009, 2011, 2012, and 2015 were characterized by extensive agricultural droughts in the semiarid region of Eritrea during the main growing season. Besides, Edossa et al. [45] find that the year 2002 was the worst drought year and about $99 \%$ of the total area of the Awash River basin was under meteorological drought.

The Belg and Kiremit seasons long-term (2001-2019) mean VCl spatial distribution is shown in Figs. 9 and 10, respectively. In the Belg season, severe droughts were observed in the central and southern parts of the basin (Fig. 9). Likewise, severe droughts in the Kiremit season were experienced in the central, eastern, and northeastern parts of the study area (Fig. 10). Conversely, none drought areas were experienced in the northern and western parts during the Belg season and in the northern, western, and southeastern parts in the Kiremit season. In Belg season, maximum severe drought areas were observed in Woyna Dega AEZ while most none drought areas were experienced in Dega and High Dega AEZs. Similarly, most severe drought vulnerable areas in the Kiremit season were observed in Woyna Dega AEZ whereas maximum none drought areas were identified in Dega AEZ.

Figure 11 shows the 2016 area coverage of $\mathrm{VCl}$ drought types during the Belg (a) and Kiremit (b) seasons, and the 2016 LULC (c) map of the Upper Awash basin. Integration of the results with the sentinel 2 LULC map revealed that forest, grassland, shrubland, crop, water, and built-up area with spatial average $B e l g \mathrm{VCl}$ values of $51.38 \%, 48.00 \%, 44.75 \%, 50.10 \%, 57.99 \%$, and $41.83 \%$, respectively. Likewise, the integration of the results with the sentinel 2 LULC map indicated that forest, grassland, shrubland, crop, water, and built-up area with areal average Kiremit $\mathrm{VCl}$ values of $50.87 \%, 45.03 \%, 42.05 \%$, $40.10 \%, 50.16 \%$, and $35.23 \%$, respectively. The areas identified with severe drought in the Kiremit season were mostly cropland areas while most severe drought areas were identified in most cropland and some builtup areas during the Belg season.
Fig. 6 The Kiremit season yearly variations of drought index (VCI) in different AEZs of Upper Awash basin during 2001-2019 periods

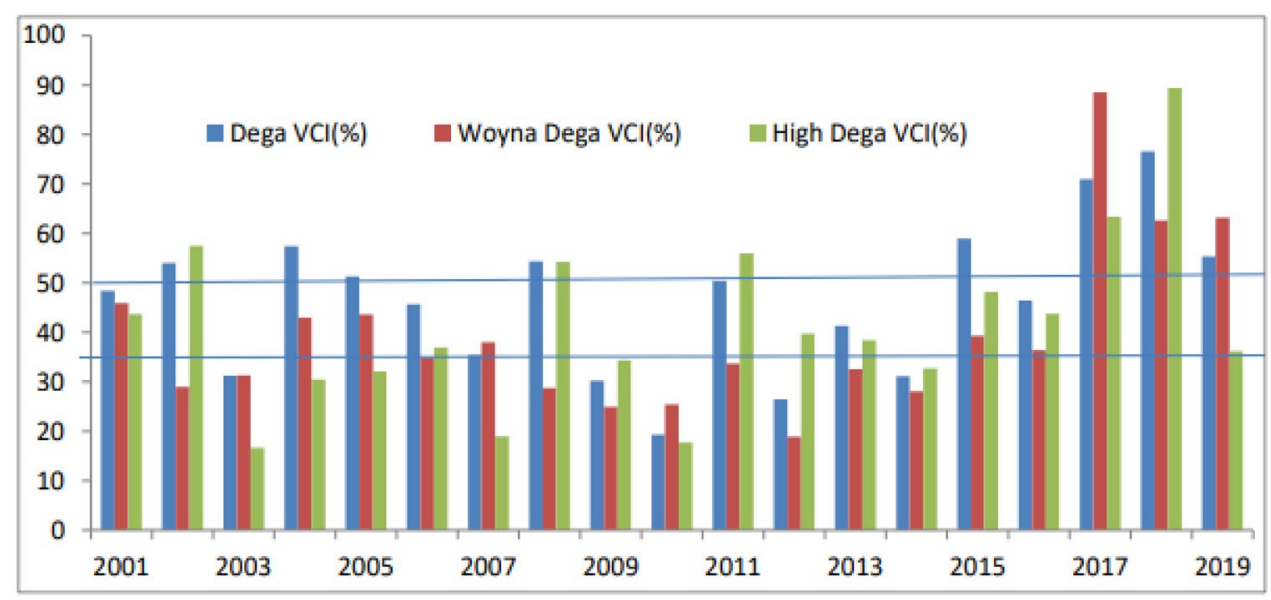




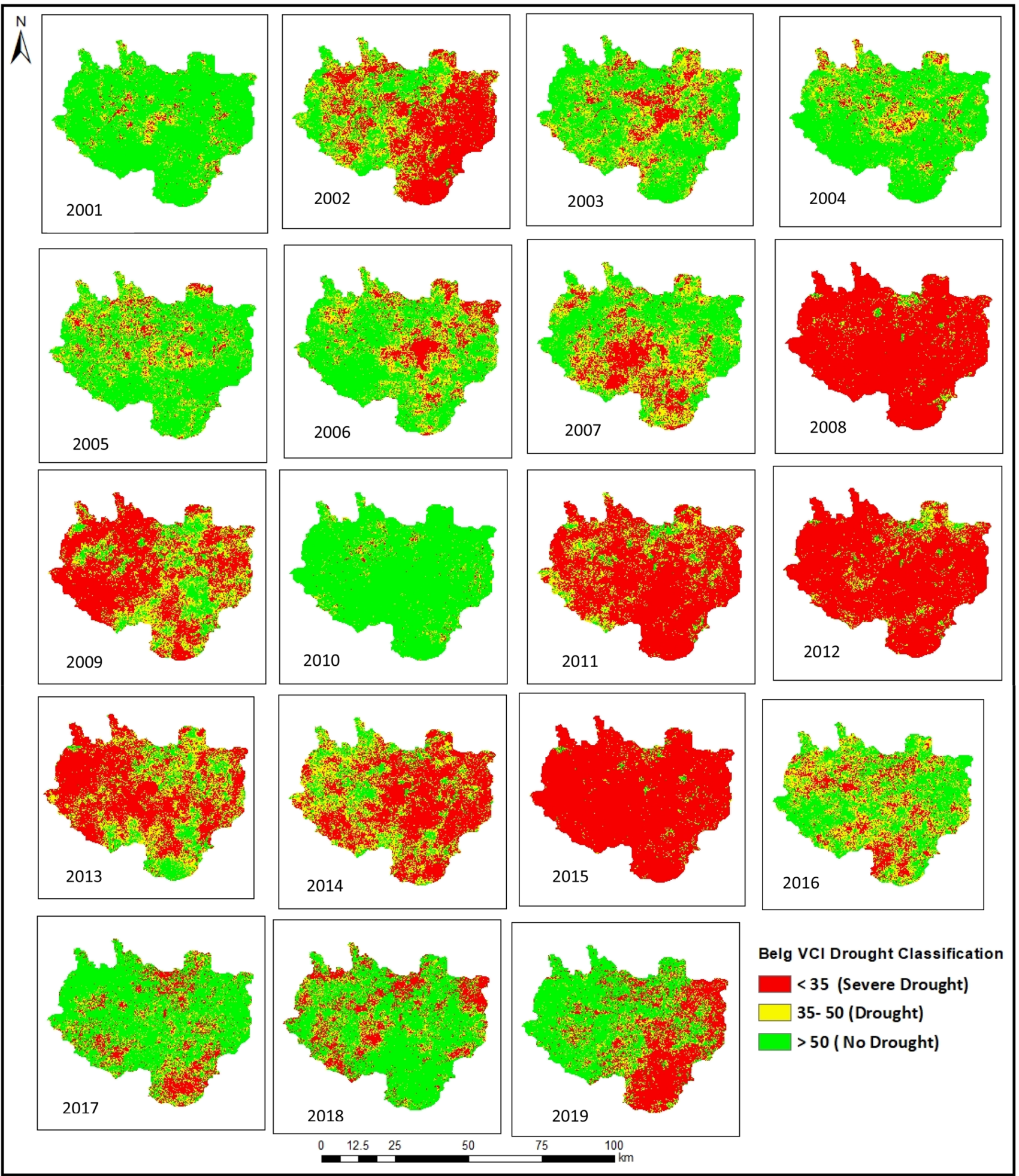

Fig. 7 The spatial and temporal distribution of pixel-based VCl over Belg season during 2001-2019 periods in the Upper Awash basin

\subsection{Spatial and temporal drought trends}

The spatial VCI trend (2001-2019) of the Upper Awash basin in the Belg season was varied spatially from -6.4 to
5.54 (Fig. 12). Negative VCl slope values were observed in the mid-northern (in and around Addis Ababa), southern, southwest, and eastern parts of the study area due to the rapid expansion of anthropogenic influences such 


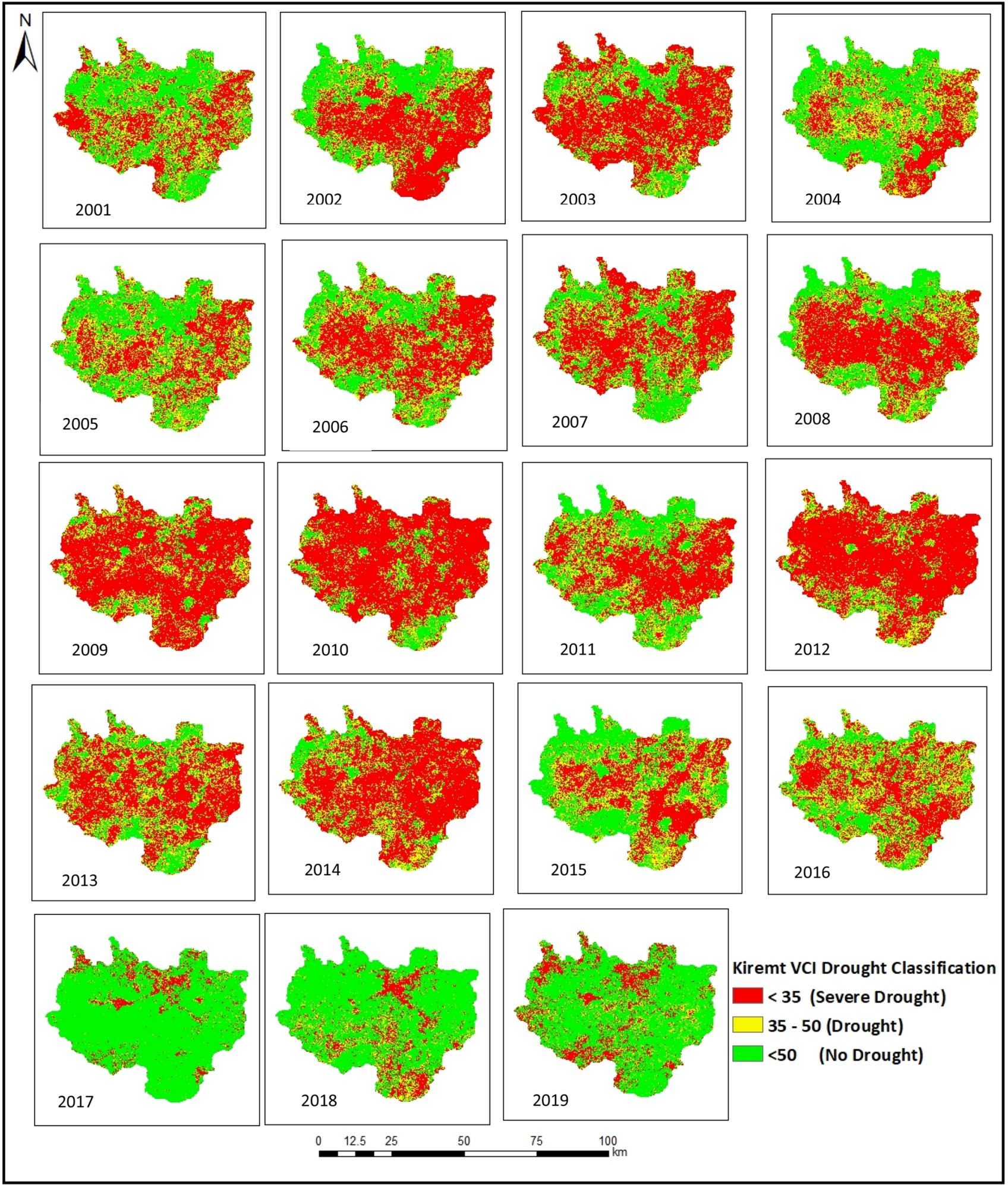

Fig. 8 The spatial and temporal distribution of pixel-based VCl over Kiremit season during 2001-2019 periods in the Upper Awash basin

as vegetation degradation, urban and industrial expansion. During the Belg season, the most negative VCl slope values were identified in the capital city of Ethiopia, Addis
Ababa. Urban expansion due to higher population invasion and rapid socio-economic development in Addis Ababa and neighboring cities inevitably reduces natural 
Fig. 9 The spatial distribution of Belg season long-term average (2001-2019) VCl of the Upper Awash basin
Fig. 10 The spatial distribution of Kiremit season long-term average (2001-2019) VCl of the Upper Awash basin
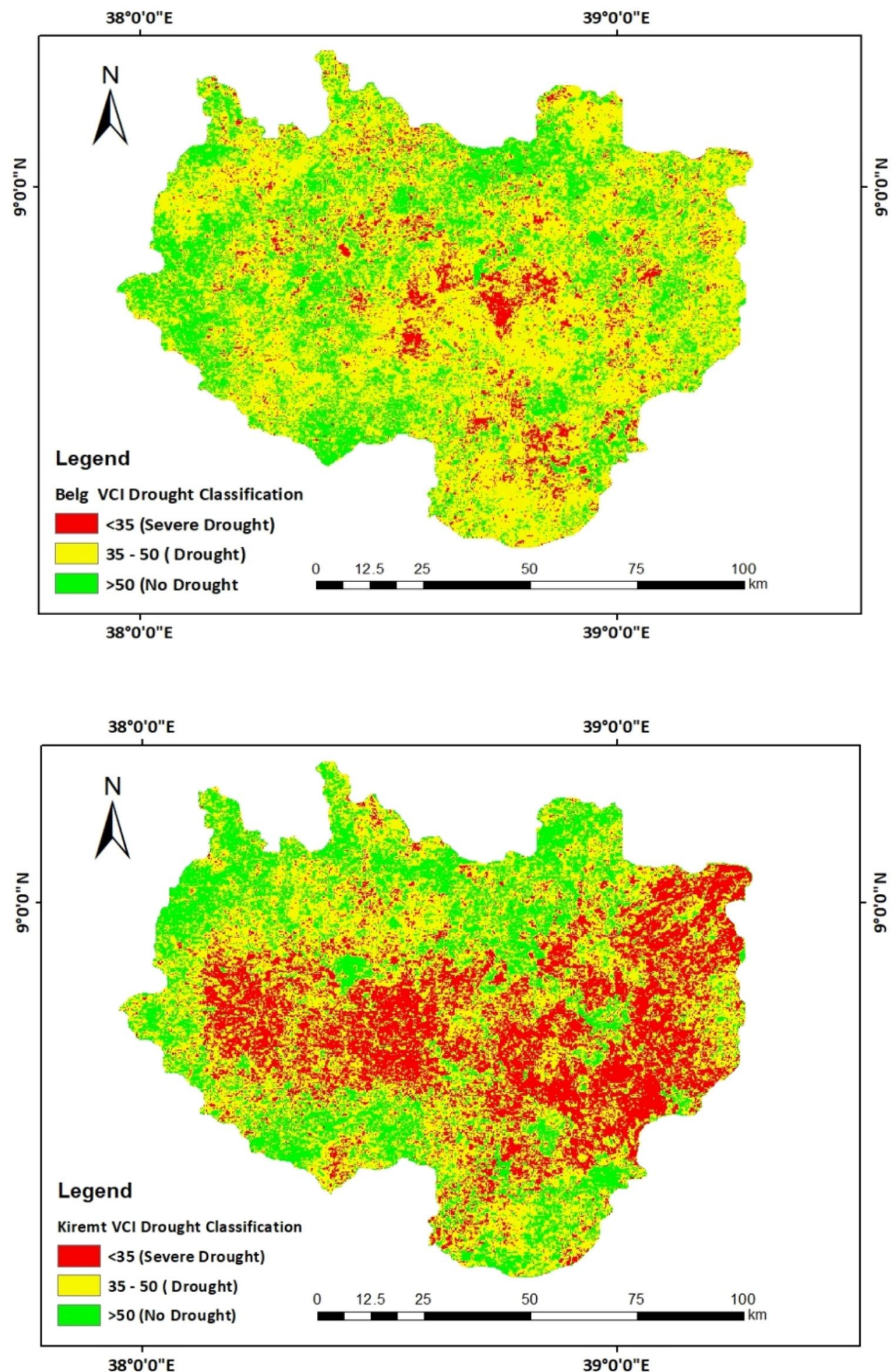

vegetation and cropland areas [80]. Shawul et al. [80] also reported reductions in forests and shrubland areas from 1974 to 2014 in the Upper Awash basin. Besides, Shawul and Chakma [81] revealed a significant increase in the area of cropland and urban areas and a declining trend in forest and shrubland in the Upper Awash basin. In turn, the reductions in forest and shrubland areas have an impact on agricultural production, leading to climate change and agricultural drought. On the contrary, positive slope values have been identified in the central and northwestern parts of the study basin. Likewise, during the Kiremit season, the VCl spatial trend (2001-2019) was varied from 


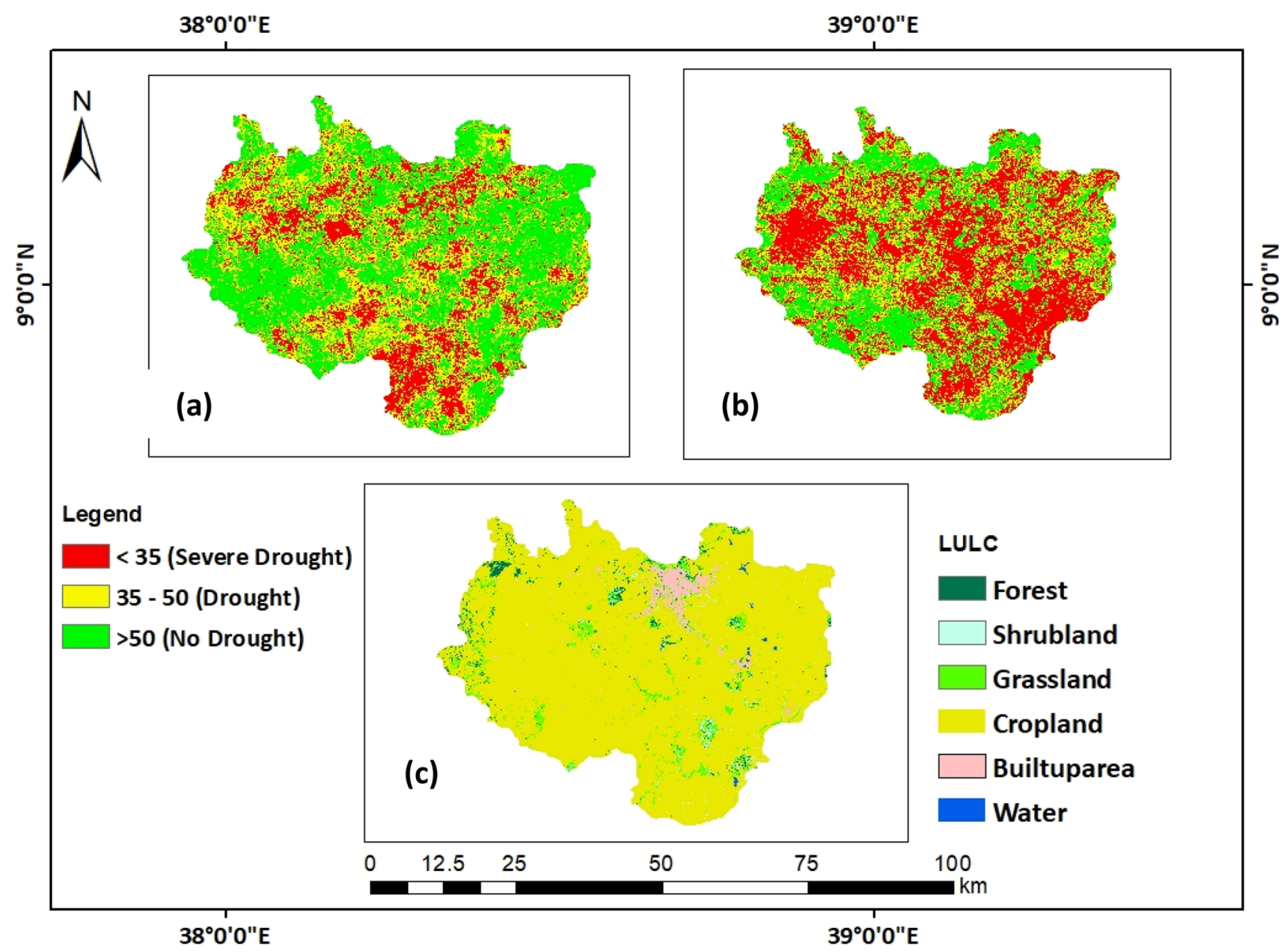

Fig. 11 The 2016 VCl drought classifications in Belg (a) and Kiremit (b) seasons and the 2016 LULC map (c) of the Upper awash basin

-6.7 to 5.8 (Fig. 13). In the Kiremit season, the negative VCI slope values were observed in the mid-northern (in and around Addis Ababa) and northwestern parts because of urban and industrial expansion. In contrast, positive $\mathrm{VCl}$ slope values were experienced in the eastern and western parts of the area (Fig. 13). The highest negative VCl trends $(-6.7--2.5)$ were experienced in the northern parts of the basin, and it indicates the potential drought and droughtvulnerable area due to reductions in forests and shrubland areas. In the Kiremit season, negative VCl slope values have been identified in the built-up area and grassland area while negative $\mathrm{VCl}$ slope values have been identified in the forest and built-up areas during the Belg season. On the contrary, positive $\mathrm{VCl}$ slope values were identified in most of the cropland areas during the Belg and Kiremit seasons. Similarly, Qian et al. [33] find that the VCI trend was increased in most agricultural areas of China from 1982 to 2010 . The negative $\mathrm{VCl}$ trend area coverage was higher in the Belg season than the Kiremit season in the Upper Awash basin. Therefore, most drought vulnerable areas were observed in the Belg season than Kiremit season during the study periods (2001-2019) of the Upper Awash basin. The Belg season VCl spatial average temporal trend was decreased from 2001 to 2019 (Table 3) and indicating the decline of vegetation growth and the rise of drought. On the contrary, the Kiremit season VCl spatial average temporal trend was increased through 2001 to 2019 (Table 3) and indicating the enhancement of vegetation growth and the decline of drought in the study area.

\subsection{Exceedance probability and return periods}

The probability of exceedance $(\mathrm{P}(\mathrm{xm}))$ of the Upper Awash basin areal average $\mathrm{VCl}$ equal to or greater than $35 \%$ and $50 \%$ during the analyzed years (2001-2019) in Belg and Kiremit season is shown in Fig. 14. The Belg season $\mathrm{VCl}$ corresponded to $\mathrm{P}(\mathrm{xm})$ of 0.65 and 0.5 , respectively, equivalent to or greater than $35 \%$ and $50 \%$. These findings indicate that in the Upper Awash basin there was a $35 \%$ chance of severe drought occurring 
Fig. 12 The Belg season VCl slope spatial distribution in the Upper Awash basin (2001-2019)
Fig. 13 The Kiremit season VCl slope spatial distribution in the Upper Awash basin (2001-2019)
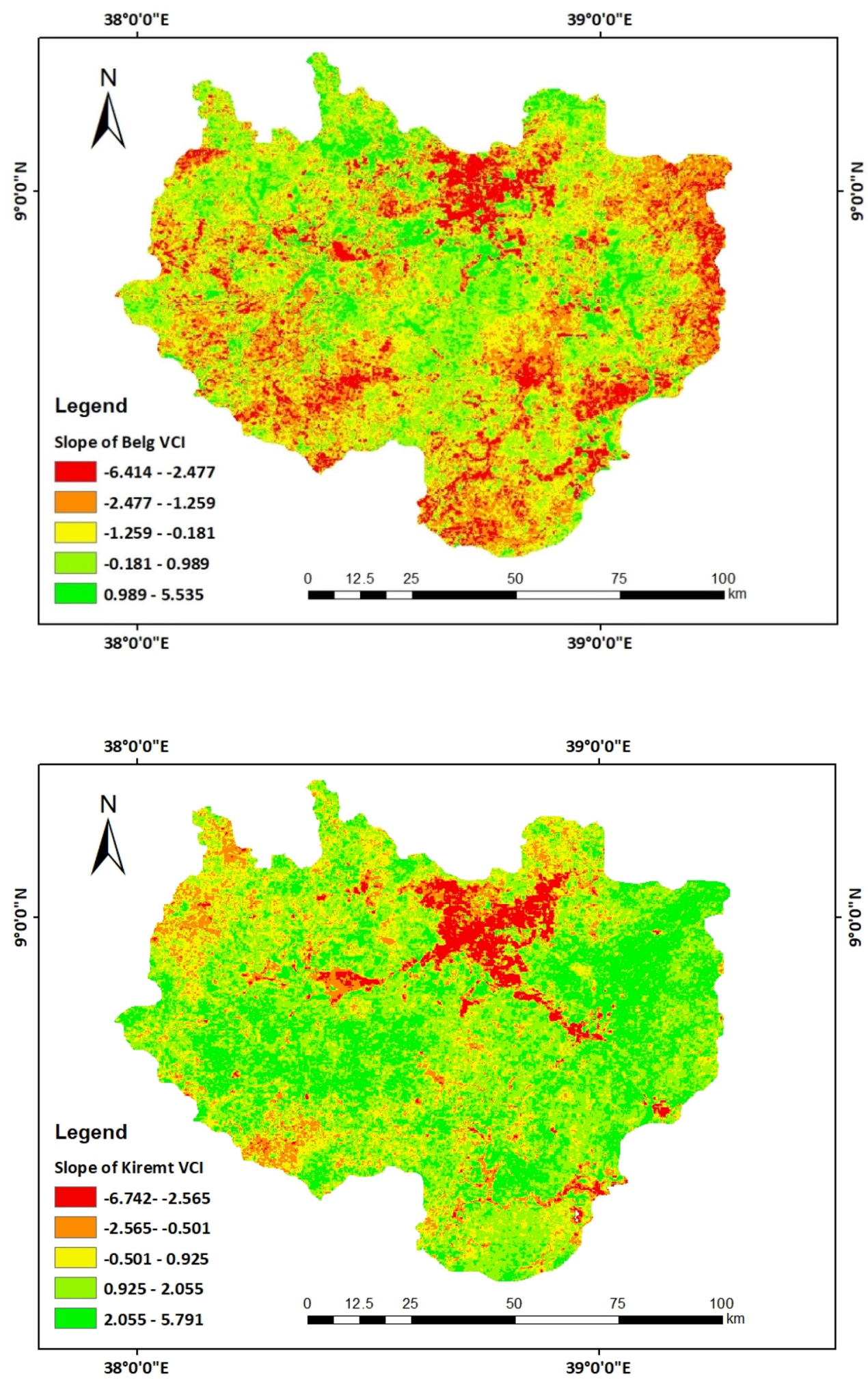

( $\mathrm{VCl}<35 \%)$ and a $50 \%$ chance of normal drought occurring $(35 \%<\mathrm{VCl}<50 \%)$. Similarly, the average $\mathrm{VCl}$ equal to or greater than $35 \%$ and $50 \%$ corresponded to $\mathrm{P}(\mathrm{xm})$ of 0.7 and 0.2 , respectively, in the Kiremit season, which forecasts the likelihood of severe drought occurring and normal drought to be $30 \%$ and $80 \%$, respectively.

The return period of the spatial average $B e l g \mathrm{VCl}$ is equivalent to or greater than $35 \%$ and $50 \%$, respectively, 
Fig. 14 The exceedance probability $(\mathrm{P}(\mathrm{xm}))$ of $\mathrm{VCl}$ of Upper Awash basin equal to or greater than $35 \%$ and $50 \%$ on Belg (a) and Kiremit (b) seasons during the analyzed years (2001-2019)
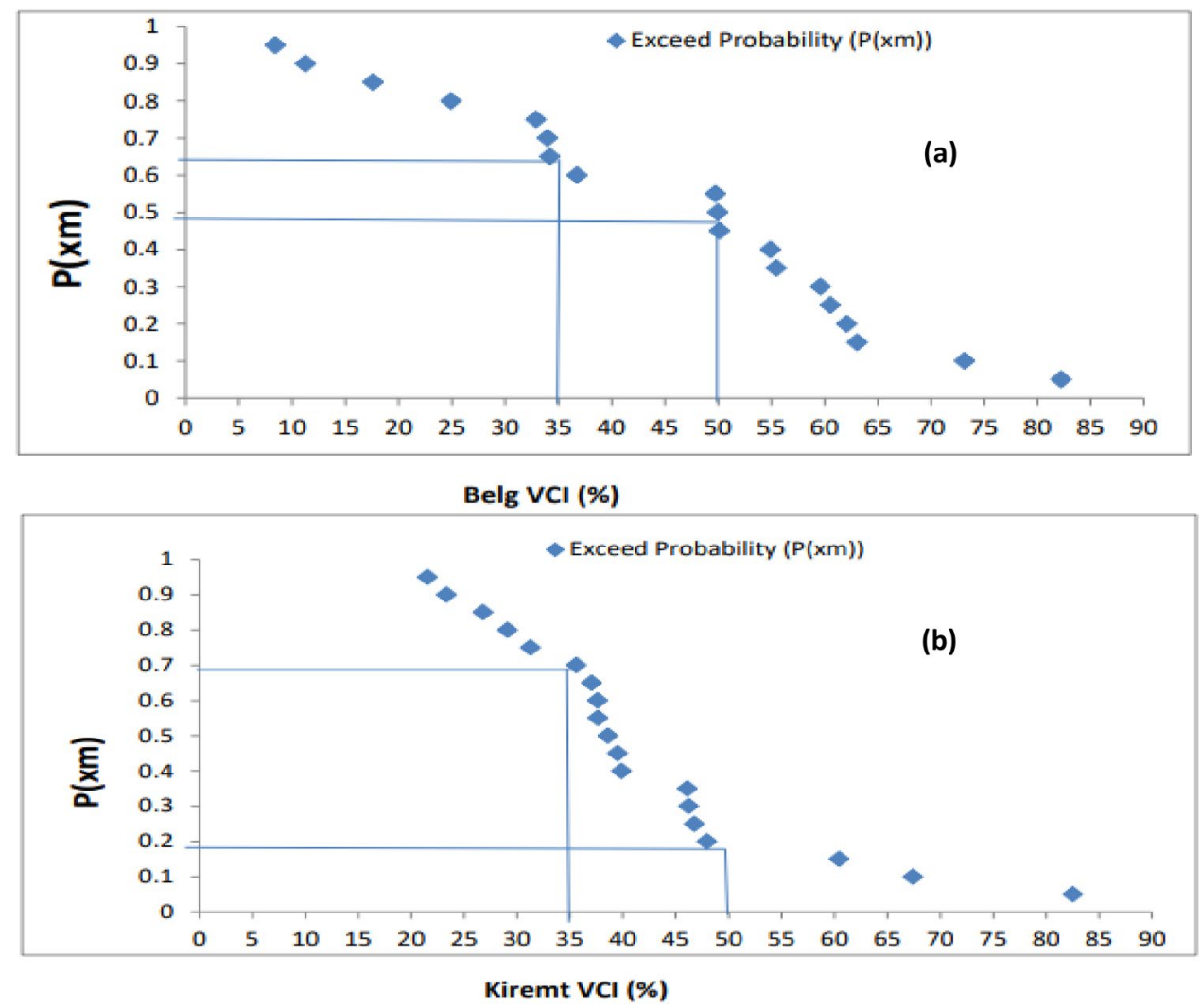

was 1.54 and 2 years. Similarly, the return periods during the Kiremit season of severe drought $(\mathrm{VCl}<35 \%)$ and normal drought $(35 \%<\mathrm{VCl}<50 \%)$ were 1.43 and 5 years, respectively. Similarly, Kogan et al. [82]] reported that droughts affected the Horn of Africa (including the Upper Awash basin) annually. Besides, Gidey et al. [75] find that, from 2001 to 2015, the incidence of agricultural drought events in the low land areas of Raya was 10-11 times higher. Moreover, Edossa et al. [45] reported that meteorological droughts occurred once in two years in the Upper Awash basin (Nazareth Area), which is consistent with the findings of this study. The normal drought return cycle $(35 \%<\mathrm{VCl}<50 \%)$ during the Kiremit season was less frequent than the Belg season. On the other hand, the return period of severe drought $(\mathrm{VCl}<35 \%)$ during the Belg season was less frequent than the Kiremt season.

\subsection{Association between $\mathrm{VCl}$ and climate variability}

The Pearson correlation coefficient $(r)$ between spatial average $\mathrm{VCl}$ and precipitation was 0.64 and 0.10 for Belg and Kiremit seasons, respectively (Table 5 ). The positive correlation between spatial mean $\mathrm{VCl}$ and precipitation implies that enhanced precipitation supports vegetation growth and drought reduction [83]. Similarly, a study conducted by Tiruneh et al. [84] reported a strong positive correlation $(r=0.62)$ between NDVI and precipitation during the Belg
Table 5 Relationship between VCl and climatic factors (LST, SST and precipitation)

\begin{tabular}{|c|c|c|c|}
\hline & $r$ & p-value & $r^{2}$ \\
\hline \multicolumn{4}{|c|}{$\begin{array}{l}\text { Correlation coefficients between VCI (\%) and precipitation } \\
(2001-2019)\end{array}$} \\
\hline Kiremit & 0.104 & 0.671 & 0.0109 \\
\hline Belg & 0.643 & 0.003 & 0.4138 \\
\hline \multicolumn{4}{|c|}{ Correlation Coefficients between VCI (\%) and LST (2001-2019) } \\
\hline Kiremit & 0.065 & 0.792 & 0.0042 \\
\hline Belg & -0.774 & 0.0001 & 0.599 \\
\hline \multicolumn{4}{|c|}{ Correlation coefficients between VCI (\%) and SST (2001-2019) } \\
\hline Kiremit & 0.163 & 0.504 & 0.0266 \\
\hline Belg & 0.319 & 0.183 & 0.1019 \\
\hline
\end{tabular}

season from 2001 to 2016 in the Upper Awash basin. The result of this study also reported a weak positive correlation $(r=0.10)$ between $\mathrm{VCl}$ and precipitation during the Kiremit season in the Upper Awash basin. This weak correlation between precipitation and $\mathrm{VCl}$ during the kiremit season may be due to the signal saturation of certain biomass values, the lack of solar radiation used for photosynthesis due to cloud. Liou and Mulualem [40] reported a strong positive correlation ( $r=0.83$ ) between NDVI and precipitation during the Kiremit season in Ethiopia from 2001 to 2018. Likewise, Measho et al. [79] reported that a strong positive correlation 
between mean annual NDVI and mean annual total precipitation in Eritrea from 2000 to 2017. Dutta et al. [85] find a good agreement between the $\mathrm{VCl}$ value and rainfall anomaly index in India. Similarly, Wan et al. [86] also reported that the linear correlation between vegetation temperature index and monthly precipitation in the southern Great Plains of the USA.

The correlation between spatial average $\mathrm{VCl}$ and land surface temperature (LST) was negative $(r=-0.77)$ and positive $(r=0.06)$ during Belg and Kiremit seasons, respectively (Table 5). These results indicate that land surface temperature (LST) was the main influencing factor on spatial average $\mathrm{VCl}$ during the Belg season. Similar to the finding of this research, Tiruneh et al. [84] find that the negative $(r=-0.67)$ and positive $(r=0.41)$ correlations between spatial average NDVI and LST during Belg and Kiremit season, respectively, in the Upper Awash basin of Ethiopia from 2001 to 2016. The positive correlation between spatial mean VCl and LST during the Kiremit season indicated that an increase in land surface temperature caused an upward trend in the $\mathrm{VCl}$, which implies a decline in drought. The result of this study was also supported by Baniya et al. [83] and reported that a positive correlation between the spatial average $\mathrm{VCl}$ and temperature in Nepal from 1982 to 2015 during annual and seasonal monsoon time scales. A study undertaken by Qian et al. [33] also reported the strong positive correlation between $\mathrm{VCl}$ and mean annual temperature in the agricultural area of China from 1982 to 2010 . The increased land surface temperature will enhance vegetation growth by an accelerated release of nutrients and improved availability from the soil until the optimum temperature for photosynthesis $[83,87]$. A similar result was also reported in this study during the Kiremit season. On the contrary, Liou and Mulualem [40] reported a strong negative correlation $(r=-0.76)$ between NDVI and LST during the Kiremit season in Ethiopia from 2001 to 2018.

The Pearson correlation coefficient $(r)$ between spatial mean VCl and SST was 0.32 and 0.106 for Belg and Kiremit seasons, respectively (Table 5). Likewise, Tiruneh et al. [84] find the positive correlation, $r=0.42$ and $r=0.22$, between the spatial mean NDVI and SST anomaly during Belg and Kiremit season, respectively, in the Upper Awash basin. Similar to the finding of this research, Philippon et al. [88] reported that a positive correlation between NDVI and NINO 3.4 SSTA in the autumn season over northwestern Africa.

\section{Conclusion}

This study investigated the spatiotemporal variability of agricultural drought and its association with climatic variables in the Upper Awash basin of Ethiopia. High spatiotemporal variability of drought was observed across the study area during Kiremit and Belg seasons. The results of this study revealed that severe droughts occurred in the years 2008, 2009, 2011, 2012, 2013, 2014, and 2015 while normal droughts were observed in 2002, 2016, and 2019 years in the Belg season. Likewise, in the Kiremit season, the severe drought years were identified in the years $2003,2009,2010,2012$, and 2014, whereas normal drought years were identified during 2001-2016 except 2003, 2009, 2010, 2012, and 2014 years in Upper Awash basin. The Belg season spatial average VCI trends were decreased, whereas the Kiremit season spatial mean VCl trends were increased during the studied periods (2001-2019). However, the decreasing and increasing trends of $\mathrm{VCl}$ were not statistically significant at a 5\% significant level. The decreasing trend of $\mathrm{VCl}$ in the Belg season indicates the increasing trend of agricultural drought while the increasing trend of $\mathrm{VCl}$ in the Kiremit season shows the decreasing trend of drought in the basin. In the Belg season, the most severe drought years were identified in Woyna Dega AEZ whereas most none drought years were found in High Dega AEZ. Similarly, during the Kiremit season, the most severe drought years were observed in Woyna Dega and High Dega AEZs, while most none drought years were experienced in Dega AEZ. In the Kiremit season, areas identified with severe droughts were mostly cropland areas, while in the Belg season, the most severe drought areas were identified in most cropland areas and some builtup areas in the basin. The return period of severe drought $(\mathrm{VCl}<35 \%)$ during the Belg season was less frequent than the Kiremt season. The correlation between spatial mean $\mathrm{VCl}$ and precipitation was 0.64 and 0.10 for Belg and Kiremit seasons, respectively. Likewise, the correlation between spatial average $\mathrm{VCl}$ and land surface temperature (LST) was negative $(r=-0.77)$ for Belg and positive $(r=0.06)$ for the Kiremit season in the basin. Moreover, the correlation between spatial mean $\mathrm{VCl}$ and Pacific Ocean sea surface temperature (SST) was 0.32 and 0.106 for Belg and Kiremit seasons, respectively. Generally, precipitation and LST were the main influencing factors on $\mathrm{VCl}$ during the Belg season in the basin. Therefore, the findings of this study can be used as a useful information source on spatiotemporal variability of drought and its association with climatic variables in the drought-prone areas of the Upper Awash basin for policy-makers and planners for establishing effective and comprehensive monitoring and early warning system to reduce the adverse impacts of drought.

Funding The research was fully self-funded.

Data availability The data for this research can be accessed from. https://lpdaac.usgs.gov/products/mod44bv006/\#tools, http://www. 
cgd.ucar.edu/cas/catalog/climind/TNI_N34/index.html, andhttps:// data.chc.ucsb.edu/products/CHIRPS-2.0/.

\section{Declarations}

Conflicts of interest The authors declare that there is no conflict of interest.

Open Access This article is licensed under a Creative Commons Attribution 4.0 International License, which permits use, sharing, adaptation, distribution and reproduction in any medium or format, as long as you give appropriate credit to the original author(s) and the source, provide a link to the Creative Commons licence, and indicate if changes were made. The images or other third party material in this article are included in the article's Creative Commons licence, unless indicated otherwise in a credit line to the material. If material is not included in the article's Creative Commons licence and your intended use is not permitted by statutory regulation or exceeds the permitted use, you will need to obtain permission directly from the copyright holder. To view a copy of this licence, visit http://creativecommons. org/licenses/by/4.0/.

\section{References}

1. Winkler K, Gessner U, Hochschild V (2017) Identifying droughts affecting agriculture in Africa based on remote sensing time series between 2000-2016: rainfall anomalies and vegetation condition in the context of ENSO. Remote Sens. https://doi.org/ $10.3390 / \mathrm{rs} 9080831$

2. Heim RR (2002) A review of twentieth-century drought indices used in the United States. Bull Am Meteor Soc 83(8):1149-1165

3. Zhang A, Jia G (2013) Monitoring meteorological drought in semiarid regions using multi-sensor microwave remote sensing data. Remote Sens Environ 134:12-23. https://doi.org/10. 1016/j.rse.2013.02.023

4. Sona NT, Chen CF, Chen CR, Chang LY, Minh VQ (2012) Monitoring agricultural drought in the lower mekong basin using MODIS NDVI and land surface temperature data. Int. J Appl Earth Ob Geoinf 18(1):417-427. https://doi.org/10.1016/j.jag. 2012.03.014

5. Udmale P, Ichikawa Y, Manandhar S, Ishidaira H, Kiem AS (2014) Farmers' perception of drought impacts, local adaptation and administrative mitigation measures in Maharashtra State India. Int J Disaster Risk Reduct 10:250-269. https://doi.org/10.1016/j. ijdrr.2014.09.011

6. AghaKouchak A, Feldman D, Hoerling M, Huxman T, Lund J (2015) Water and climate: recognize anthropogenic drought. Nature 524(7566):409-411. https://doi.org/10.1038/524409a

7. Van Loon AF et al (2016) Drought in a human-modified world: Reframing drought definitions, understanding, and analysis approaches. Hydrol Earth Syst Sci 20(9):3631-3650. https://doi. org/10.5194/hess-20-3631-2016

8. Guo E et al (2017) Assessing spatiotemporal variation of drought and its impact on maize yield in Northeast China. J Hydrol 553:231-247. https://doi.org/10.1016/j.jhydrol.2017.07.060

9. Cunha APM, Alvalá RC, Nobre CA, Carvalho MA (2015) Monitoring vegetative drought dynamics in the Brazilian semiarid region Agric For. Meteorol 214-215:494-505. https://doi.org/ 10.1016/j.agrformet.2015.09.010

10. Zhang J, Mu Q, Huang J (2016) Assessing the remotely sensed drought severity index for agricultural drought monitoring and impact analysis in North China. Ecol Indic 63:296-309. https:// doi.org/10.1016/j.ecolind.2015.11.062

11. Cong D, Zhao S, Chen C, Duan Z (2017) Characterization of droughts during 2001-2014 based on remote sensing: a case study of Northeast China. Ecol Inform 39:56-67. https://doi.org/ 10.1016/j.ecoinf.2017.03.005

12. Rulinda CM, Dilo A, Bijker W, Stein A (2012) Characterising and quantifying vegetative drought in East Africa using fuzzy modelling and NDVI data. J Arid Environ 78:169-178. https://doi.org/ 10.1016/j.jaridenv.2011.11.016

13. Liang L, Sun Q, Luo X, Wang J, Zhang L, Deng M et al (2017) Long-term spatial and temporal variations of vegetative drought based on vegetation condition index in China. Ecosphere. https://doi.org/10.1002/ecs2.1919

14. Mendicino G, Senatore A, Versace P (2008) A Groundwater Resource Index (GRI) for drought monitoring and forecasting in a mediterranean climate. J Hydrol 357(3-4):282-302. https://doi.org/10.1016/j.jhydrol.2008.05.005

15. Mirabbasi R, Anagnostou EN, Fakheri-Fard A, Dinpashoh Y, Eslamian S (2013) Analysis of meteorological drought in northwest Iran using the Joint deficit index. J Hydrol 492:3548. https://doi.org/10.1016/j.jhydrol.2013.04.019

16. Shen Q, Liang L, Luo X, Li Y, Zhang L (2017) Analysis of the spatial-temporal variation characteristics of vegetative drought and its relationship with meteorological factors in China from 1982 to 2010. Environ Monit Assess. https://doi.org/10.1007/ s10661-017-6187-9

17. Han Y, Li Z, Huang C, Zhou Y, Zong S, Hao T et al (2020) Monitoring droughts in the greater changbai mountains using multiple remote sensing-based drought indices. Remote Sens. https://doi.org/10.3390/rs12030530

18. Townshend JRG, Justice CO (2002) Towards operational monitoring of terrestrial systems by moderate-resolution remote sensing. Remote Sens Environ 83(1-2):351-359. https://doi. org/10.1016/S0034-4257(02)00082-2

19. Johnson GE, Achutuni VR, Thiruvengadachari S, Kogan F (1993) The role of NOAA satellite data in drought early warning and monitoring: selected case studies", in drought assessment. Manage, Plan: Theory Case Stud 1993:31-47

20. Peters AJ, Walter-Shea EA, Ji L, Viña A, Hayes M, Svoboda MD (2002) Drought monitoring with NDVI-based standardized vegetation index. Photogramm Eng Remote Sens 68(1):71-75

21. Choi M, Jacobs JM, Anderson MC, Bosch DD (2013) Evaluation of drought indices via remotely sensed data with hydrological variables. J Hydrol 476:265-273. https://doi.org/10.1016/j. jhydrol.2012.10.042

22. Kogan FN (1990) Remote sensing of weather impacts on vegetation in non-homogeneous areas. Int J Remote Sens 11 (8):1405-1419. https://doi.org/10.1080/014311690089551 02

23. Hou YY, He YB, Liu QH, Tian GL (2007) Research progress on drought indices". Chin J Ecol 26(6):892-897

24. Tonini F, Lasinio GJ, Hochmair HH (2012) Mapping return levels of absolute NDVI variations for the assessment of drought risk in Ethiopia. Int J Appl Earth Obs Geoinf 18(1):564-572. https:// doi.org/10.1016/j.jag.2012.03.018

25. Tadesse $T$ et al (2015) Assessing the vegetation condition impacts of the 2011 drought across the U.S. southern great plains using the vegetation drought response index VegDRI. J Appl Meteorol Climatol 54(1):153-169. https://doi.org/10.1175/ JAMC-D-14-0048.1

26. Skakun S, Kussul N, Shelestov A, Kussul O (2016) The use of satellite data for agriculture drought risk quantification in Ukraine. Geomat Nat Hazards Risk 7(3):901-917. https://doi.org/10.1080/ 19475705.2015.1016555 
27. Kogan FN (1995) Droughts of the late 1980s in the United States as derived from NOAA polar-orbiting satellite data. Bull Am Meteorol Soc 76(5):655-668. https://doi.org/10.1175/15200477(1995)076\%3c0655:DOTLIT\%3e2.0.CO;2

28. Kogan FN (1995) Application of vegetation index and brightness temperature for drought detection. Adv Sp Res 15(11):91-100. https://doi.org/10.1016/0273-1177(95)00079-T

29. Liu WT, Kogan FN (1996) Monitoring regional drought using the vegetation condition index. Int J Remote Sens 17(14):27612782. https://doi.org/10.1080/01431169608949106

30. Domenikiotis C, Spiliotopoulos M, Tsiros E, Dalezios NR (2004) Early cotton yield assessment by the use of the NOAA/AVHRR derived vegetation condition index (VCl) in Greece. Int J Remote Sens 25(14):2807-2819. https://doi.org/10.1080/0143116031 0001632729

31. Quiring SM, Ganesh S (2010) Evaluating the utility of the vegetation condition index ( $\mathrm{VCl})$ for monitoring meteorological drought in Texas. Agric For Meteorol 150(3):330-339. https:// doi.org/10.1016/j.agrformet.2009.11.015

32. Deng M, Di L, Han W, Yagci AL, Peng C, Heo G (2013) Webservice-based monitoring and analysis of global agricultural drought. Photogramm Eng Remote Sens 79(10):929-943. https://doi.org/10.14358/PERS.79.10.929

33. Qian X, Liang L, Shen Q, Sun Q, Zhang L, Liu Z et al (2016) Drought trends based on the $\mathrm{VCl}$ and its correlation with climate factors in the agricultural areas of China from 1982 to 2010. Environ Monit Assess. https://doi.org/10.1007/s10661-016-5657-9

34. Kogan F, Salazar L, Roytman L (2012) Forecasting crop production using satellite-based vegetation health indices in Kansas, USA. Int J. Remote Sens 33(9):2798-2814. https://doi.org/10. 1080/01431161.2011.621464

35. Jiao W, Zhang L, Chang Q, Fu D, Cen Y, Tong Q (2016) Evaluating an enhanced vegetation condition index ( $\mathrm{VCl})$ based on VIUPD for drought monitoring in the continental United States. Remote Sens. https://doi.org/10.3390/rs8030224

36. Wang K, Li T, Wei J (2019) Exploring drought conditions in the three river headwaters region from 2002 to 2011 using multiple drought indices. Water (Switz). https://doi.org/10.3390/w1102 0190

37. Ayana EK, Ceccato P, Fisher JRB, DeFries R (2016) Examining the relationship between environmental factors and conflict in pastoralist areas of East Africa. Sci Total Environ 557-558:601-611. https://doi.org/10.1016/j.scitotenv.2016.03.102

38. Gebremeskel G, Tang Q, Sun S, Huang Z, Zhang X, Liu X (2019) Droughts in East Africa: causes, impacts and resilience. Earth Sci Rev 193:146-161. https://doi.org/10.1016/j.earscirev.2019. 04.015

39. Qu C, Hao X, Qu JJ (2019) Monitoring extreme agricultural drought over the Horn of Africa (HOA) using remote sensing measurements. Remote Sens. https://doi.org/10.3390/rs110 80981

40. Liou YA, Mulualem GM (2019) Spatio-temporal assessment of drought in Ethiopia and the impact of recent intense droughts. Remote Sens 11(15):1-19. https://doi.org/10.3390/rs11151828

41. Philip S, Kew SF, van Oldenborgh GJ, Otto F, O'Keefe S, Haustein $\mathrm{K}$ et al (2018) Attribution analysis of the Ethiopian drought of 2015. J Clim 31(6):2465-2486. https://doi.org/10.1175/ JCLI-D-17-0274.1

42. Funk $C$, Peterson $P$, Landsfeld $M$, Pedreros $D$, Verdin J, Shukla $S$ et al (2015) The climate hazards infrared precipitation with stations - A new environmental record for monitoring extremes. Sci Data. https://doi.org/10.1038/sdata.2015.66

43. Camberlin $P$ (1997) Rainfall anomalies in the source region of the Nile and their connection with the Indian summer monsoon. J Clim 10(6):1380-1392. https://doi.org/10.1175/1520-0442
44. Desalegn CE, Babel MS, Das GA, Seleshi BA, Merrey D (2006) Farmers' perception of water management under drought conditions in the Upper Awash basin Ethiopia. Int J Water Resour Dev 22(4):589-602. https://doi.org/10.1080/079006206007797 23

45. Edossa DC, Babel MS, Gupta AD (2010) Drought analysis in the Awash River basin. Ethiopia Water Resour Manag 24(7):14411460. https://doi.org/10.1007/s11269-009-9508-0

46. Abdisa A (2015) Seasonal climate prediction for rain-fed crop production planning in the Upper Awash Basin , central high land of Ethiopia. Unpubl Master thesis, Haramaya University

47. Tesfamariam E (2016) Characterizing the Hydro-climatic Deficient Moisture to Monitor Agricultural Drought by Using Remote Sensing: The Case of Upper Awash Basin, Ethiopia. Unpubl Master thesis, Addis Ababa University

48. Mengistu D (2008) Regional flood frequency analysis for Upper Awash Sub Basin (UPSTREAM OF KOKA). Unpubl Master thesis, Addis Ababa University

49. Babu A (2009) The impact of Pacific sea surface temperature on the Ethiopian rainfall". Workshop on High Impact Weather Predictability Information Systemfor Africa and AMMA THORPEX Forecasters. Trieste, Italy: National Meteorological Agency

50. Zaroug M (2010) The connections of Pacific SST and drought over East Africa". DEWFORA meeting at ECMWF, Improved Drought Early Warning and FORecasting to strengthen preparedness and adaptation to droughts in Africa (DEWFORA), United Kingdom, 4-5 October

51. Gella GW (2018) Impacts of integrated soil and water conservation programs on vegetation regeneration and productivity as indicator of ecosystem health in Guna-Tana watershed: evidences from satellite imagery. Environ Syst Res 7(1):1-14. https://doi.org/10.1186/s40068-018-0105-1

52. Rocchini $D$, Metz $M$, Ricotta $C$, Landa M, Frigeri A, Neteler $M$ (2013) Fourier transforms for detecting multitemporal landscape fragmentation by remote sensing. Int J Remote Sens 34(24):8907-8916. https://doi.org/10.1080/01431161.2013. 853896

53. Asfaw A, Simane B, Hassen A, Bantider A (2018) Variability and time series trend analysis of rainfall and temperature in northcentral Ethiopia: a case study in Woleka sub-basin. Weather Clim Extrem 19:29-41. https://doi.org/10.1016/j.wace.2017.12.002

54. Dinku T et al (2018) Validation of the CHIRPS satellite rainfall estimates over eastern Africa. QJRMeteorol Soc 144:292-312. https://doi.org/10.1002/qj.3244

55. Belay AS, Fenta AA, Yenehun A, Nigate F, Tilahun SA, Moges MM et al (2019) Evaluation and application of multi-source satellite rainfall product CHIRPS to assess spatio-temporal rainfall variability on data-sparse western margins of Ethiopian highlands. Remote Sens 11(22):1-22. https://doi.org/10.3390/rs11222688

56. Dinku T, Funk C, Peterson $P$, Maidment R, Tadesse T, Gadain H et al (2018) Validation of the CHIRPS satellite rainfall estimates over eastern Africa. Q J R Meteorol Soc 144:292-312. https://doi. org/10.1002/qj.3244

57. Traore SS, Landmann T, Forkuo EK, Traore PCS (2014) Assessing long-term trends In vegetation productivity change over the Bani River basin in mali West Africa. J GeogrEarth Sci. https:// doi.org/10.15640/jges.v2n2a2

58. Ly S, Charles C, Degré A (2011) Geostatistical interpolation of daily rainfall at catchment scale: the use of several variogram models in the Ourthe and Ambleve catchments, Belgium. Hydrol Earth Syst Sci 15:2259-2274. https://doi.org/10.5194/ hess-15-2259-2011

59. Alemu MM, Bawoke GT (2019) Analysis of spatial variability and temporal trends of rainfall in Amhara region. J Water Clim Chang, Ethiopia. https://doi.org/10.2166/wcc.2019.084 
60. Tesfamariam BG, Gessesse B, Melgani F (2019) Characterizing the spatiotemporal distribution of meteorological drought as a response to climate variability: the case of rift valley lakes basin of Ethiopia. Weather Clim Extrem 26:100237. https://doi.org/10. 1016/j.wace.2019.100237

61. Mao K, Qin Z, Shi J, Gong P (2005) A practical split-window algorithm for retrieving land-surface temperature from MODIS data. Int J Remote Sens 26(15):3181-3204. https://doi.org/10.1080/ 01431160500044713

62. Mao K, Shi J, Li ZL, Tang H (2007) An RM-NN algorithm for retrieving land surface temperature and emissivity from EOS/MODIS data. J Geophys Res Atmos. https://doi.org/10.1029/2007J D008428

63. Kogan FN (1997) Global drought watch from space. Bull Am Meteorol Soc 78(4):621-636. https://doi.org/10.1175/1520-0477

64. Rimkus E, Stonevicius E, Kilpys J, Maclulyte V, Valiukas D (2017) Drought identification in the eastern Baltic region using NDVI. Earth Syst Dyn 8(3):627-637. https://doi.org/10.5194/ esd-8-627-2017

65. Zhang G, Xu X, Zhou C, Zhang H, Ouyang H (2011) Responses of grassland vegetation to climatic variations on different temporal scales in Hulun Buir Grassland in the past 30 years. J Geogr Sci 21(4):634-650. https://doi.org/10.1007/s11442-011-0869-y

66. Mekonen AA, Berlie AB, Ferede MB (2020) Spatial and temporal drought incidence analysis in the northeastern highlands of Ethiopia. Geoenviron Disasters. https://doi.org/10.1186/ s40677-020-0146-4

67. Sen PK (1968) Estimates of the regression coefficient based on Kendall's Tau. J Am Stat Assoc 63(324):1379-1389. https://doi. org/10.1080/01621459.1968.10480934

68. Yue S, Pilon P, Cavadias G (2002) Power of the Mann-Kendall and Spearman's rho tests for detecting monotonic trends in hydrological series. J Hydrol 259:254-271. https://doi.org/10.1016/ S0022-1694(01)00594-7

69. Mann HB (1945) Nonparametric tests against trend. Econometrica 13(3):245. https://doi.org/10.2307/1907187

70. Hamlaoui-Moulai L, Mesbah M, Souag-Gamane D, Medjerab A (2013) Detecting hydro-climatic change using spatiotemporal analysis of rainfall time series in Western Algeria. Nat Hazards 65(3):1293-1311. https://doi.org/10.1007/s11069-012-0411-2

71. Reddy A, PJR, (2008) Text Book of Hydrology. University Science Press, New Delhi

72. Guo W, Ni X, Jing D, Li S (2014) Spatial-temporal patterns of vegetation dynamics and their relationships to climate variations in Qinghai Lake Basin using MODIS time-series data. J Geogr Sci 24(6):1009-1021. https://doi.org/10.1007/s11442-014-1134-y

73. Mu S et al (2013) Spatio-temporal dynamics of vegetation coverage and its relationship with climate factors in Inner Mongolia. China. J Geogr Sci 23(2):231-246. https://doi.org/10.1007/ s11442-013-1006-x

74. Ayehu GT, Tadesse T, Gessesse B, Dinku T (2018) Validation of new satellite rainfall products over the Upper Blue Nile Basin. Atmos Meas Tech 11(4):1921-1936. https://doi.org/10.5194/ amt-11-1921-2018

75. Gidey E, Dikinya O, Sebego R, Segosebe E, Zenebe A (2018) Analysis of the long-term agricultural drought onset, cessation, duration, frequency, severity and spatial extent using Vegetation Health Index (VHI) in Raya and its environs. Environ Syst Res. https://doi.org/10.1186/s40068-018-0115-z

76. Hurni $H$ (1998) Agroecological belts of Ethiopia explanatory notes on three maps at a scale of 1:1,000,000. Soil Conservation Research Programme Ethiopia Research Report, Addis Ababa
77. Altieri MA et al (2015) Agroecology and the design of climate change-resilient farming systems: review article. Sustain Dev, Agron. https://doi.org/10.1007/s13593-015-0285-2.Springer

78. Luana S, Hou X (2015) Wang Y (2015) Assessing the accuracy of srtm dem and aster dem datasets for the coastal zone of shandong province. Eastern China Polish Maritime Res 22(86):15-20. https://doi.org/10.1515/pomr-2015-0026,2015S1

79. Measho $S$, Chen B, Trisurat $Y$, Pellikka $P$, Guo L, Arunyawat $S$ et al (2019) Spatio-temporal analysis of vegetation dynamics as a response to climate variability and drought patterns in the Semiarid Region. Remote Sens, Eritrea. https://doi.org/10.3390/ RS11060724

80. Shawul AA, Chakma S, Melesse AM (2019) The response of water balance components to land cover change based on hydrologic modeling and partial least squares regression (PLSR) analysis in the Upper Awash Basin. J Hydrol. Reg Stud 26:100640. https:// doi.org/10.1016/j.ejrh.2019.100640

81. Shawul AA, Chakma S (2019) Spatiotemporal detection of land use/land cover change in the large basin using integrated approaches of remote sensing and GIS in the Upper Awash basin. Ethiopia Environ Earth Sci 78(5):141

82. Kogan F, Guo W, Strashnaia A, Kleshenko A, Chub O, Virchenko O (2016) Modelling and prediction of crop losses from NOAA polar-orbiting operational satellites. Geomatics Nat Hazards Risk 7(3):886-900. https://doi.org/10.1080/19475705.2015.1009178

83. Baniya B, Tang Q, Xu X, Haile GG, Chhipi-Shrestha G (2019) Spatial and temporal variation of drought based on satellite derived vegetation condition index in Nepal from 1982-2015. Sensors. https://doi.org/10.3390/s19020430

84. Tiruneh GB, Gessesse B, Besha T, Workineh G (2018) Evaluating the Association between Climate Variability and Vegetation Dynamics by Using Remote Sensing Techniques The Case of Upper Awash Basin Ethiopia. World J Agric Res, 6(4):153-66. https://doi.org/10.12691/wjar-6-4-6.

85. Dutta D, Kundu A, Patel NR, Saha SK, Siddiqui AR (2015) Assessment of agricultural drought in Rajasthan (India) using remote sensing derived vegetation condition index (VCI) and standardized precipitation index (SPI). Egypt J Remote Sens Sp Sci 18(1):53-63. https://doi.org/10.1016/j.ejrs.2015.03.006

86. Wan Z, Wang P, Li X (2004) Using MODIS land surface temperature and normalized difference vegetation index products for monitoring drought in the southern great plains. Int J Remote Sens 25(1):61-72. https://doi.org/10.1080/014311603100011 5328

87. Michaletz ST, Cheng D, Kerkhoff AJ, Enquist BJ (2014) Convergence of terrestrial plant production across global climate gradients. Nature 512(1):39-43. https://doi.org/10.1038/nature13470

88. Philippon N, Martiny N, Camberlin P, Hoffman MT, Gond V (2014) Timing and patterns of the ENSO signal in Africa over the last 30 years: insights from normalized difference vegetation index data. J Clim 7(7):2509-2532. https://doi.org/10.1175/ JCLI-D-13-00365.1

Publisher's Note Springer Nature remains neutral with regard to jurisdictional claims in published maps and institutional affiliations. 